CuPAUAM.17-1990, 219-253

\title{
LOS MOSAICOS DE LA VILLA ROMANA DE TORRE-LA CRUZ (VILLAJOYOSA, ALICANTE)
}

\author{
ANTONIO ESPINOSA RUIZ (1)
}

\section{Resumen}

Se estudian varios fragmentos de mosaico, algunos inéditos, pertenecientes a la zona de los balnea de la villa bajoimperial de Torre-la Cruz (Villajoyosa, Alicante). Se ofrece su descripción completa, acompañada de los primeros calcos realizados directamente sobre las piezas originales. Este trabajo supone una interpretación de la distribución espacial de cada fragmento, así como de la cronología de los dos niveles superpuestos de estos balnea y de sus mosaicos.

\section{Résumén}

On étudie plusieurs fragments de mosaïque, quelques uns inédits, appartenants à la zone des balnea de la villa basse-impériale de Torre-la Cruz (Villajoyosa, Alicante). On offre leur description complète, accompagnée des premiers calques réalisés directement sur les pièces originales. Ce travail établi une interpretation de la distribution spatiale de chaque fragment et aussi la chronologie des deux niveaux superposés de ces balnea et de leurs mosaïques.

El yacimiento de Torre-la Cruz está situado sobre el cerro de la Torre de Abajo y sus laderas, en la partida de Les Xauxelles, perteneciente al término municipal de Villajoyosa, a unos 1700 m. al NW de esta población (Fig. 1). Esta pequeña elevación, de materiales terciarios, tiene una extensión de $0.6 \mathrm{Ha}$., su altitud alcanza los $76 \mathrm{~m}$. y su elevación sobre la llanura pleistocénica

(1) Hemos de expresar nuestro agradecimiento, en primer lugar, a la Dra. Carmen Fernández Ochoa por sus valiosas orientaciones durante la realización de este trabajo, así como a los Dres. Lorenzo Abad, Enrique Llobregat, Manuel Bendala y Angel Fuentes por su lectura del texto. Al Dr. Llobregat hemos de agradecerle igualmente las facilidades prestadas para la documentación de los fragmentos del Museo Arqueológico Provincial de Alicante. Del mismo modo debemos una referencia de gratitud a D. José Payá Nicolau, director de la Casa de Cultura de Villajoyosa, por sus valiosas informaciones y su contínua colaboración, así como al Excmo. Ayuntamiento de la ciudad. Una parte de este trabajo pudo realizarse gracias a una Ayuda a la Investigación del Instituto de Estudios aJuan GilAlbert", de la Excma. Diputación de Alicante, en su edición de 1987. 
circundante es de $15 \mathrm{~m}$. El dominio visual de extensos terrenos agrícolas, así como la situación del lugar junto a un cruce de caminos favoreció su ocupación desde la Edad del Bronce. Posteriormente parece asentarse sobre él un poblado ibérico que nos es, todavía, muy mal conocido. Otro tanto sucede con el asentamiento altoimperial, probablemente una villa, del que apenas sabemos nada (2).

La fase más conocida se corresponde con el período bajoimperial, cuando se construye una villa de carácter monumental. Ya en 1921 se publica un artículo, dándola a conocer, en la revista La Esfera (Soler, 1921), acompañado de una fotografía del mosaico C (vid. infra), todavía en perfecto estado de conservación. Pocos años más tarde, en 1926 y 1934, el entonces propietario de la finca, D. Jaime Silvestre Martínez, levantó tanto una parte de este pavimento como de la orla del que decoraba el apodyterium (mosaico $\mathrm{D}$, vid. infra).

La mayor parte de la información que poseemos se la debemos a J. Belda, quien efectuó una excavación parcial de la ladera meridional del cerro en los años 1946 y 1947 (3). En el curso de estos trabajos se exhumó unos balnea y sus alrededores, hallándose distintos fragmentos de mosaico in situ. Algunos de ellos fueron levantados y depositados en el Museo Arqueológico Provincial de Alicante (fragmentos A, B 1, B 2 y C). Los datos publicados por este autor (Belda, 1947) son fundamentales a la hora de acometer una reconstrucción de la situación original de cada fragmento, así como una interpretación cronológica del conjunto. Como veremos más adelante, el sector de los balnea presenta dos fases sucesivas. Denominaremos A y B a los mosaicos que sabemos pertenecientes al nivel inferior, y $\mathrm{C}$ y D a los del superior. Los distintos fragmentos se identificarán con números correlativos.

En este trabajo hemos recogido la totalidad de los grandes fragmentos conservados tanto el Museo Etnográfico e Histórico de Villajoyosa (D 1, D 2, D 3 y D 4) como en el Museo Arqueológico Provincial de Alicante (4). De todos ellos presentamos un calco realizado sobre el original. Asimismo hemos reproducido aquí una fotografía del fragmento D 5 publicada por Belda, dado que esta pieza se halla en una colección particular a la que todavía no hemos tenido acceso, si bien esperamos poder documentar directamente en breve este interesante panel.

Presentaremos, en primer lugar, un catálogo de las piezas, indicando en cada una de ellas sus principales características materiales, formales y estilísticas, para lo cual utilizaremos, siempre que sea posible, tanto la numeración como la nomenclatura AIEMA (Blanchard et al., 1973). A continuación ofreceremos una breve introducción general a cada uno de los motivos utilizados, seguida de un análisis de los paralelos más directos. Eludiremos, conscientemente, su enumeración indiscriminada, limitándonos a citar aquéllos que puedan aportar alguna información que interese a nuestro estudio. Por último, trazaremos una visión general en la que intentaremos valorar las aportaciones de los pavimentos de Torre-la Cruz a los estudios de musivaria antigua, señalando sus posibles vinculaciones con talleres de la zona.

(2) Hemos llevado a cabo un estudio completo sobre la problemática general de este yacimiento en la Memoria de Licenciatura Arqueología Romana de La Vila Joiosa, realizada bajo la dirección de la Dra. Fernández Ochoa. Su lectura tuvo lugar el día 1 de Octubre de 1990 en el Departamento de Prehistoria y Arqueología de la Universidad Autónoma de Madrid.

(3) De estos trabajos se da cuenta en Belda, 1946, 1947 y 1948.

(4) En este último se conservan numerosos fragmentos de pequeño tamaño, cuyo estudio estamos acometiendo en la actualidad. 


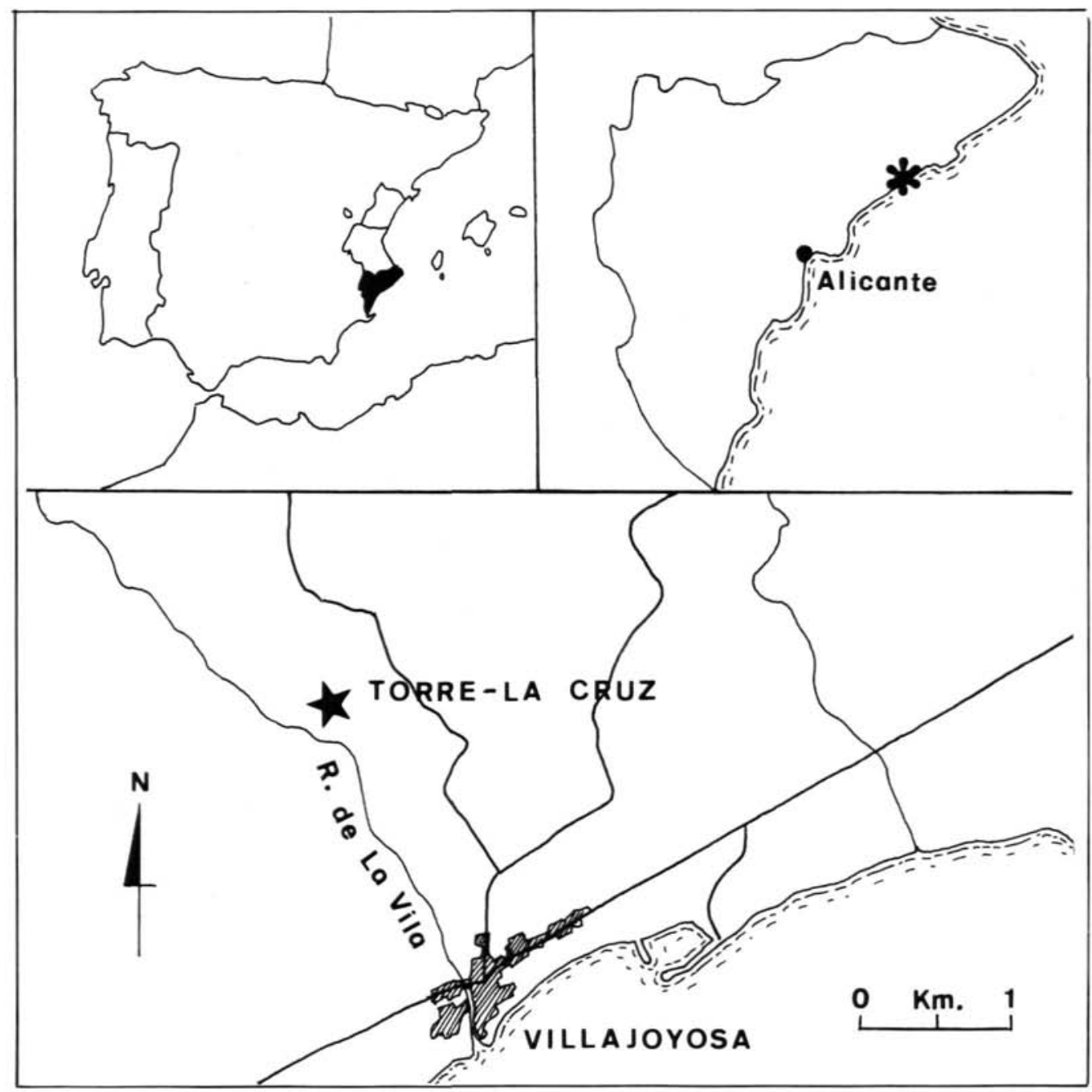

Figura 1

\section{CATALOGO}

\section{A. Mosaico con roseta de triángulos (Figs. 3 y 6 )}

El fragmento que presentamos corresponde al ángulo $\mathrm{N}$ del pavimento de una estancia destruida, de carácter indeterminado, a la que daba acceso el pasillo acodado del nivel inferior de las termas por su extremo sudoriental. Entre ambos espacios mediaba un umbral de $60 \mathrm{~cm}$. de ancho, consistente, según Belda, en un gran adobe flanqueado por dos sillarejos.

Contamos únicamente con breves referencias de aquel autor (1947, 183-184, fig. 33, 3 y lám. LXX, 2) y de Lafuente (1959, n 165, lám. XXVI). 
Presenta teselas de colores blanco, negro, rojo y ocre, de tamańo y forma irregulares. Las primeras, de mármol, miden entre 1 y $2 \mathrm{~cm}$. de lado, mientras las rojas, de ladrillo, y las ocres son en su mayor parte de forma oblonga, con una media de 1 por $1.5 \mathrm{~cm}$. Teselas por $\mathrm{dm}^{2}: 55$. Es de notar que este pavimento presenta unas características similares a las que veremos en el mosaico B, por lo que ambos debieron ejecutarse contemporáneamente, formando parte del nivel inferior de las termas de Torre-la Cruz.

Su descripción formal es como sigue: fragmento del ángulo de un motivo circular enmarcado en un paralelepípedo. Consta de: filete negro doble que enmarca toda la composición; en el ángulo, dos triángulos negros inscritos sobre fondo blanco, enmarcados por un triángulo de hipotenusa curvilínea en cuyos lados se dispone un denticulado (AIEMA 144) en negro que enlaza con el marco y con la orla; ésta última se dispone en forma circular alrededor del campo, y contiene una trenza polícroma de dos cabos (AIEMA 194) de dos teselas, uno rojo y el otro ocre, ambos con ribete blanco de una tesela; en el campo nos encontramos con una roseta de triángulos curvilíneos (AIEMA 531) de colores negro, rojo y ocre, cuyo estado fragmentario impide reconstruir su diseño original. El triángulo ocre presenta una irregularidad, al ser de menor tamaño y estar situado a media altura.

El motivo de la roseta de triángulos curvilíneos es propio de los mosaicos romanos, que no lo toman de otra manifestación artística (Ovadiah, 1980, 144) y aparece ya en ejemplos pompeyanos del s. I a.C. Parece derivar de los clípeos o escudos musivos que aparecen en mosaicos helenísticos de los ss. II y I a.C., por lo común con la representación central del gorgoneion. Aunque ésta perdura en algunos ejemplares romanos, pronto se sustituirá por rosetas geométricas o, menos frecuentemente, por temas figurados e incluso por el espacio en blanco (Balil, 1964, 85$100)$.

El tema presenta una larga tradición itálica, desarrollada durante los dos primeros siglos de la Era (Blake, 1930, 115-117). Se populariza sobre todo en la segunda mitad del s. II, y continúa siendo abundante durante el s. III (Luzón, 1988, 226-227), desde cuyos inicios se desarrollan algunas versiones polícromas, alternándose triángulos de distintos colores, como sucede en nuestro caso. Parece resurgir en la temática pavimental en fechas avanzadas del s. IV (Balil, 1965 a), apareciendo en mosaicos cristianos como motivo central.

En Hispania puede situarse cronológicamente entre la segunda mitad del s. I y finales del s. V o comienzos del VI (Mondelo, 1985, 119). Existe una serie de pavimentos en los que este tema se representa en blanco y negro, acompañado o no de elementos polícromos aislados o incluso, como veremos, formando parte de conjuntos mosaísticos polícromos (5). También se conocen ejemplares que presentan triángulos polícromos (6), de lo que se infiere

(5) Como sucede en ejemplos de la villa de La Quintilla (Ramallo 1985, 91-92, nº 76, lám. XLII; Ramallo, 1984, 28-29), Badalona (Barral 1978, 83-87, n 57, láms. XLV, 2 y XLVII; Balil, 1964, 85-100, $\mathrm{n}^{\circ}$ 6, láms. III yV, 1), Ampurias (Barral 1979, 75; Almagro Basch, 1968, lám. IX), Itálica (Luzón, 1988, fig. 20), Carmona (Luzón, 1988, fig. 21; Hernandez Díaz et al., 1943, 90, fig. 74), Linares (Luzón, 1988, fig. 22; Blázquez, 1981, $\mathrm{n}^{\circ}$ 50, lám. 58), Póvoa de Cós (Portugal) (Nóbrega, 1951, 143-149, fig. 1, lám. I), Mérida (Blanco, 1978 a, 46, nº 46, lám. 81 a; 48, n 54, lám. 86) o en Mataró (Barral, 1978, 105-106 y 109-111, n 106, láms. LXI, 1 y LXIII). De otro ejemplo emeritense tan sólo quedan indicios (Blanco, 1978 a, 33, no 13, lám. 24 a). Distinto es el esquema de las rosetas de otro mosaico hallado en esta misma ciudad (García Sandoval, 1966; Blanco, 1978 a, 42).

(6) Vid. Blanco, 1978 a, 27, n 1, lám. I; Mondelo, 1985, 116-119, n 4, fig. 6; Sánchez Real, 1949, 224, fig. 2, láms. I, 2 y II, 1. Luzón (1988) propuso la existencia de tres grupos, de los cuales los ejemplos de la Península 


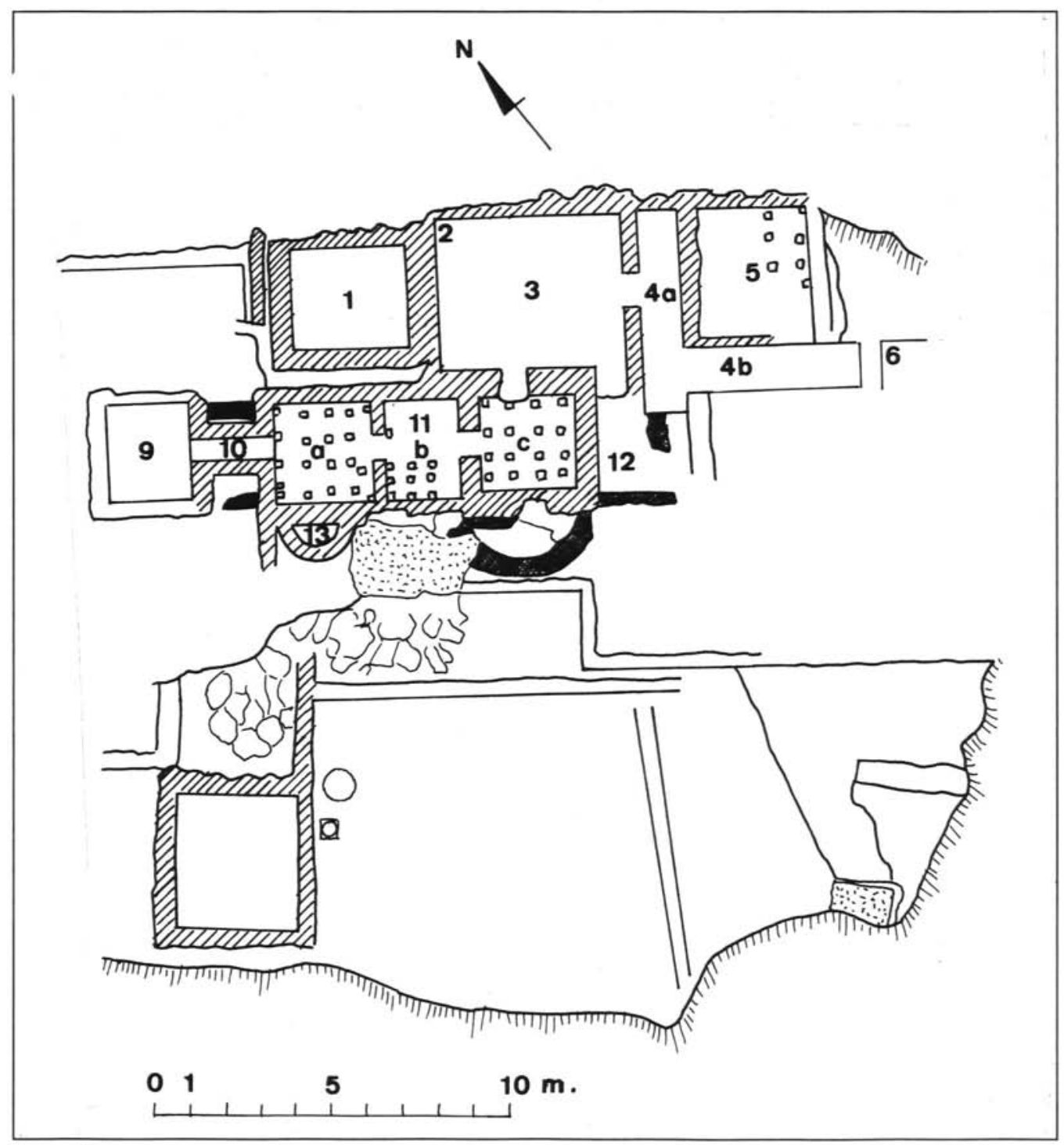

Figura 2

que el tema acaba impregnándose, en ocasiones, de la policromía dominante desde, al menos, comienzos del s. III.

El motivo se basa, en su expresión genuina, en ciertos principios geométricos, como la proporcionalidad de los triángulos, que se ve alterada en la variante que presentamos.

La roseta suele estar circundada por una orla. No es raro que, como en nuestro caso, ésta muestre un motivo de trenza, utilizado sobre todo a partir del s. II d. C., especialmente en los mosaicos polícromos (Mondelo, 1985). 
Las dimensiones totales del cuadrado llegan a alcanzar, en uno de los paralelos hispanos que hemos citado, $4.73 \mathrm{~m}$. de lado, pero se constata una mayor frecuencia entre, aproximadamente, 2 y $2.5 \mathrm{~m}$. (en 6 de los 7 casos cuyas dimensiones hemos podido recoger). No faltan ejemplares de menor porte, aunque no disponemos de sus medidas exactas. El tamaño del cuadrado que enmarca el mosaico de La Vila Joiosa resulta algo menor de lo normal para los ejemplares hispanos que conocemos, al poderse estimar en unos $132 \mathrm{~cm}$.

En las enjutas del marco se colocaban variados elementos decorativos, entre los que destacan al principio, como puede verse en los ejemplares que hemos citado, algunos símbolos de Neptuno, como los delfines, los tridentes o las espadillas. Más adelante predominará un variado repertorio de elementos figurados o vegetales (Mondelo, 1985), pero raramente se utilizará motivos geométricos, como sucede en el caso que nos ocupa.

Por lo que se refiere al número de anillos, se documenta en Hispania una amplia gama, que va desde los 4 a los 19, con una mayor frecuencia en 9. El fragmento conservado de nuestro mosaico no permite adivinarlo con exactitud, si bien difícilmente podría superar la cifra de dos, singularidad que lo asemeja a los ejemplos galos (cf. Luzón, 1988).

Creemos, a tenor de todo lo expuesto, que la aportación cronológica de este mosaico al contexto general del nivel más antiguo de las termas de Torre-la Cruz, consiste en marcar un límite inferior en los comienzos del s. III.

\section{B. Mosaico de chevrons (Figs. 4, 5 y 6 ).}

Dos fragmentos del tapiz que pavimentaba el pasillo inferior. Se trata de un mosaico polícromo, con teselas de tamaño y forma irregulares, entre 3.5 y $0.5 \mathrm{~cm}$. de lado. Las blancas calizas y las negras, de mármol, presentan una media de 2 por $2.5 \mathrm{~cm}$. de lado, y una forma algo oblonga. Las rojas, ocres y blancas marmóreas, similares a las del mosaico A, son de forma también oblonga y dimensiones más regulares, con una media de 1.5 por $2 \mathrm{~cm}$. de lado, algo menor en las dos últimas. Hay que señalar que estas teselas de mármol blanco se reservan al motivo de lacería del ángulo. Teselas por $\mathrm{dm}^{2}$ : aproximadamente 31, salvo la lacería, donde alcanza las 62 .

B 1. Fragmento del extremo sudoriental del mosaico (7). Dimensiones estimadas: anchura de la orla $28 \mathrm{~cm}$.; anchura del campo $65.5 \mathrm{~cm}$.; anchura total $121.5 \mathrm{~cm}$.; anchura del panel de círculos $30 \mathrm{~cm}$.

Consta de: filete negro simple; panel perpendicular rectangular imbricado con la orla sin solución de continuidad que presenta una hilera de círculos tangentes al interior (semicírculos en los extremos) y otra de semicírculos al exterior (cuartos de círculo en los extremos), trazados en filete negro simple, alternativamente blancos y negros, sobre fondo rojo; orla de losanges (AIEMA 92), cuya disposición en zig-zag determina espacios triangulares a ambos lados, decorados con un triángulo negro inscrito en otro blanco; filete negro simple; en el campo, dos hileras

Ibérica pertenecerían al Occidental, de tradición itálica, caracterizado por la bicromía de los triángulos, a lo sumo combinado con motivos polícromos en su medallón central o en las esquinas. La existencia de rosetas de triángulos polícromos demuestra, sin embargo, una adaptación a las nuevas tendencias en Hispania. La práctica ausencia del tema en mosaicos africanos (vid. Fradier-Martin, 1976, lám. s/n) ha servido, por otra parte, para apoyar la revisión de la tesis tradicional sobre el africanismo de los mosaicos españoles, defendida por Balil (1965 b, $36 \mathrm{ss}$.).

(7) Así lo demuestran la comparación con una fotografia publicada por Belda (1947, lám. LXX, 2) y la diferente anchura de los dos tramos de este pasillo, apreciable en el fragmento B 2. 

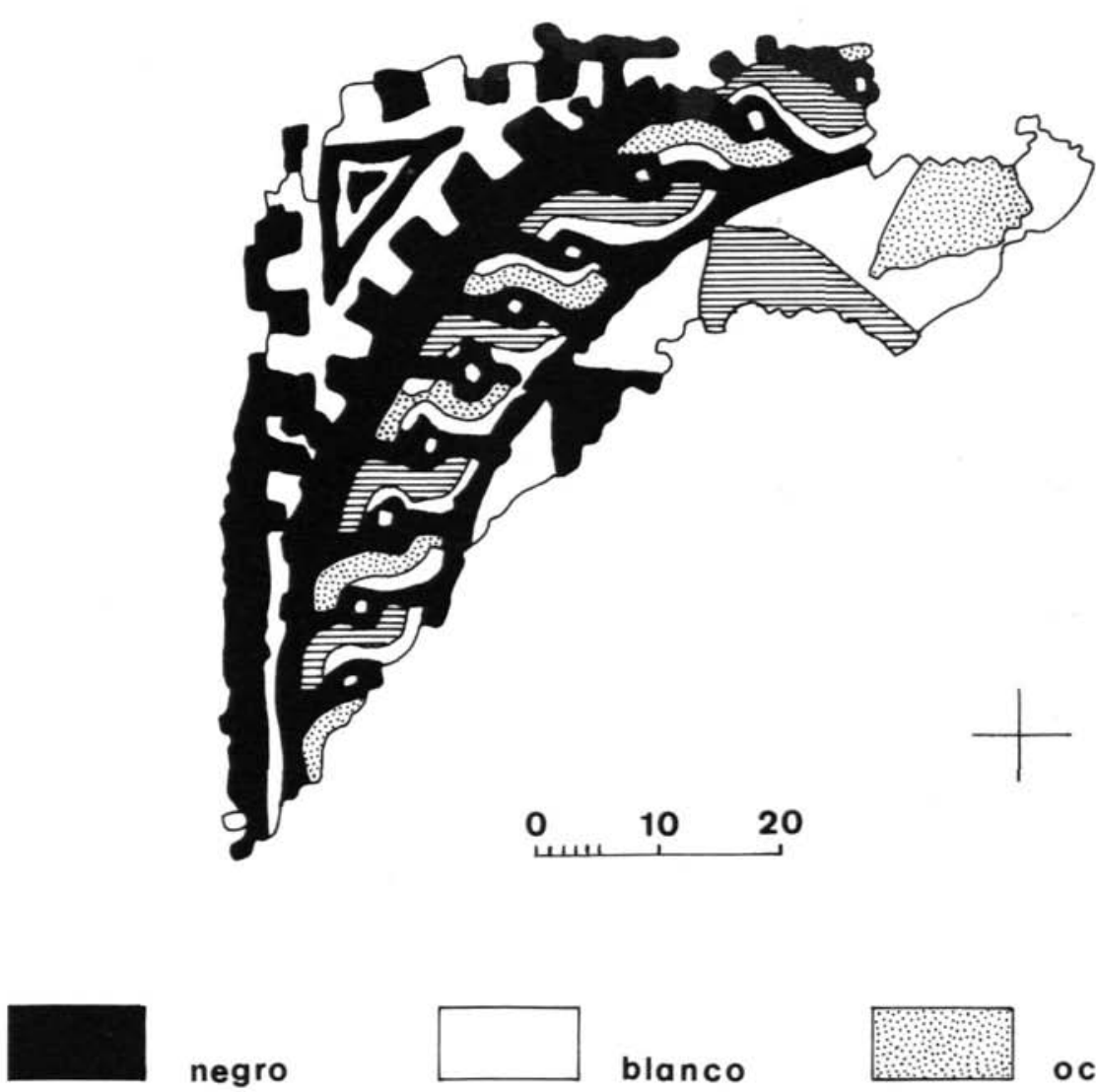

blanco

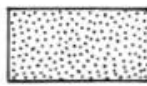

ocre

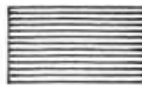

rojo

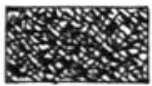

azul

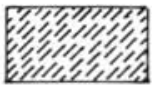

amarillo

Figura 3

longitudinales de chevrons (AIEMA 309), realizados mediante filetes simples sucesivamente blancos, rojos y negros, poco regulares (Fig. 4).

B 2. Fragmento de características similares a las del anterior, correspondiente al ángulo del corredor. En la confluencia de las hileras dobles de chevrons de ambos sectores, se dispone un cuadrado ligeramente oblongo que inscribe un motjwe de lacería de cuatro cabos, alternativamente ocres y rojos, de dos teselas, ribeteados al exterior por sendos filetes blancos simples. En el espacio triangular del ángulo se conserva un resto de venera esquemática, realizada con los mismos elementos que los chevrons.

Dimensiones estimadas del sector NE-SW del pasillo: anchura de la orla 28; del campo 57; total $113 \mathrm{~cm}$. De este modo, la anchura del sector NW-SE del pasillo es aproximadamente 8.5 
$\mathrm{cm}$. mayor que la de aquél. En lo que respecta a la lacería, se enmarca en un rectángulo de 46.5 por $44 \mathrm{~cm}$. (Fig. 5).

Bibliografía: Belda (1947, Fig. 32, láms. LXIX, 3 y LXX, 2 y 3); Lafuente (1959, 69, nos. 166 y 167 , láms. XXVI y XXVII).

Los escasos paralelos hispanos de la orla que conocemos son de fecha tardía, entre la segunda mitad del s. IV y comienzos del V (8).

Por lo que se refiere al motivo del campo, éste se utiliza ya en mosaicos bícromos de tradición itálica. Sin embargo, su proliferación corre paralela a la del estilo polícromo africano, especialmente a partir de finales del s. II y durante los dos siguientes, alcanzando incluso los siglos V y VI. Su diseño encaja muy bien en el acusado geometrismo de las nuevas tendencias. La policromía, al dotarlo de vistosidad, lo hace incluso apropiado para cubrir grandes espacios, como sucede en Torre-la Cruz.

No son numerosos los ejemplos polícromos hallados en la Península, fechables entre los siglos III y IV. Podemos diferenciar dos técnicas de realización: en la primera, las teselas que forman los chevrons se disponen escalonadamente (9), agrupándose en ocasiones en cuadrados de dos por dos o incluso más; en la segunda, las teselas se disponen de forma lineal, como en el caso que nos ocupa (10).

Ambas técnicas están representadas en numerosos pavimentos norteafricanos, como en Volubilis (Thouvenot 1948 b, 140, lám. IX, 1), Hadrumetum (Foucher, 1958, 13-14, lám. III d; 21, lám. VI b), Thuburbo Maius (11), Utica (Duliere et al., 1974, 45, n 197 a, lám. XXX; Alexander et al., 1973, 126-128, n 145, lám. LVIII) o Timgad (Germain, 1969, nº 185, lám. LX; nº 158, lám. L). Igualmente las encontramos en abundantes ejemplos de Antioquía, fechados en su práctica totalidad entre 235 y 475 (Levi, 1947).

En Italia parece ponerse de moda en fecha ya tardía. Así, lo tenemos bien documentado en Rávena. En el Palacio de Teodorico se conservan varios ejemplares datados, en conjunto, entre mediados y finales del s. VI (Berti, 1976, nos. 41, 42 y 62). Señalaremos la disposición lineal, no escalonada, de las teselas.

Se trata de un motivo más apropiado, y posiblemente por ello más utilizado, para los mosaicos polícromos que para los bícromos, al crear un efecto de degradación cromática que sugiere un sentido del movimiento, muy adecuado al pavimento de un corredor como el de Torre-la Cruz. Este efectismo fue aprovechado en la decoración mosaística del fondo de numerosas piscinas, como hemos visto. Ello supone un empleo frecuente del tema en relación con el agua, cuya superficie ondulante sugiere.

Por lo que se refiere al motivo que decora los paneles de los extremos, creemos que se trata de un remedo de las imitaciones de opus sectile en mosaico, muy típicas de los ejemplos norteafricanos, especialmente entre finales del s. III y el s. V (12). Tampoco falta en Antioquía, parti-

(8) Fernández-Galiano, 1987, 118, B-3, fig. 187, lám. LX; Blázquez, 1982 a, 36, nº 26, fig. 3.

(9) En arc de ciel, según la nomenclatura AIEMA. Vid. Barral, 1978, 105-106, $\mathrm{n}^{\circ} 106$, figs. LXI y LXIII, 2; Blázquez-Ortego, 1983, $\mathrm{n}^{\circ} 41$.

10) Vid. Blanco, 1978 a, 33, láms. 22 b y 22 a. Este mosaico, fechado en el S. IV, constituye uno de los paralelos más claros.

(11) Ben Abed et al., 1985, 101-103, nos. 235 y 236, láms. XLV y LVII; Alexander et al., 1980, nos. 45 a, 97 a, 101 y 105).

(12) Vid. Thouvenot, 1958, 58, lám. XIV, 4; Germain, 1969, nos. 4, 68, 179, 194, 195 y 196. 


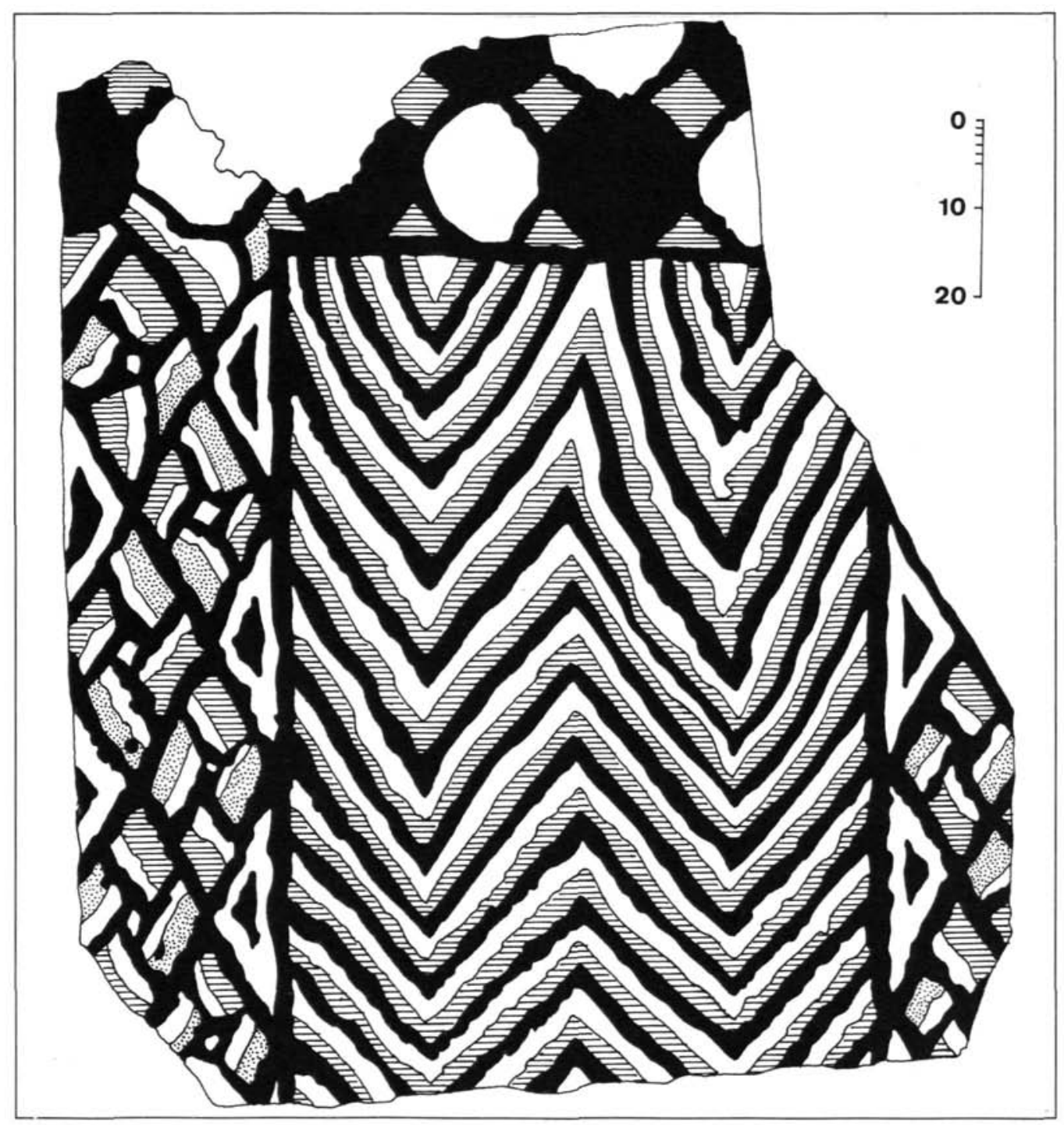

Figura 4

cularmente durante el s. V (13), o en Susa (14). Otros paralelos pueden encontrarse en los siglos III y IV en Italia: así en Roma (Morricone, 1967, n 84, Fig. XVII y nos. 90-91, Fig. XXII), en Ostia (Beccati, 1961, 210-211, n 401, Fig. 71) o en la Villa Spigarelli de Antium (Berti, 1976,

(13) Levi, 1947, 307, lám. CXXII a; 316, láms. CXXIX a, c y d.

(14) Vid. Foucher, 1960, 96, n 57215, lám. LVIII c (ęfinales del s. III?). 
$\mathrm{n}^{\circ}$ 45, Fig. XXXIX). Por otra parte, en el palacio de Teodorico de Rávena se conservan ejemplares del primer cuarto del s. VI (Berti, 1976, n 44, fig. XXXVII y no 58, fig. XLVI). También lo encontramos en Cerdeña (Angiolillo, 1981, 47, $\mathrm{n}^{\circ}$ 42, fig. XLIX), y tenemos un ejemplo francés en Autun (Blanchet, 1909, n 811).

$\mathrm{Al}$ parecer, este tema está bien documentado en pavimentos hispanos del s. IV (BlázquezGonzález Navarrete, 1974, nota 90), si bien lo encontramos todavía en la primera mitad del s. VI (15). En cualquier caso, este tipo de motivos circulares, de tintas planas, es propio de mosaicos tardíos, y se utiliza sobre todo en paneles secundarios, como sucede en el ejemplar que nos ocupa.

Los mosaicos A y B, pertenecientes al nivel inferior de las termas de Torre-la Cruz fueron, en nuestra opinión, realizados por un taller probablemente local, no sabemos si itinerante, que imitó motivos decorativos que estaban de moda en la época con materiales de baja calidad, muy poco acabados, y con una técnica muy poco perfeccionada, puesta de manifiesto en la extremada irregularidad de las teselas y en la propia ejecución de los temas.

Es de notar que los motivos utilizados en el mosaico B, de marcada influencia norteafricana, (chevron lineales, círculos en tintas planas, lacerías) se encuentran entre los más repetidos en conjuntos de baja época como el palacio de Teodorico de Rávena. Ello no lleva, en nuestra opinión, a otra conclusión que no sea el carácter tardío de la pieza que nos ocupa, en fuerte contraste con el innegable arcaísmo de los mosaicos del nivel superior, que estudiaremos a continuación. El pavimento B no parece, sin embargo, aportar mayor precisión a la fecha del nivel inferior de las termas de Torre-la Cruz con respecto al anterior.

\section{Mosaico de peltas (figs. 7 y 12 )}

Extremo del tapiz que pavimentaba el corredor ceñido a la pared sudoriental del apodyterium, en el nivel superior de los balnea. Dimensiones máximas conservadas: anchura $109.5 \mathrm{~cm}$., longitud $71 \mathrm{~cm}$.; anchura media de la orla $19.5 \mathrm{~cm}$.; anchura del campo $60 \mathrm{~cm}$.

Mosaico bícromo, en negro sobre fondo blanco. Teselas de mármol, de $1 \mathrm{~cm}$ por término medio. Teselas por $\mathrm{dm}^{2}: 64$.

Descripción formal: filete negro simple; línea de ojivas dentro de semicírculos secantes trazados (AIEMA 181), adornados con pequeños triángulos (hederae esquemáticas) en sus extremos; en el interior de las enjutas aparece un ribete simple, en ocasiones relleno en negro; en los espacios intermedios de los semicírculos una florecilla en aspa; filete negro simple; en el campo tenemos pares de peltas tangentes adosadas alternativamente horizontales y verticales (AIEMA 455) con apéndice de punta de flecha (Fig. 7).

Este pavimento se encontraba sobrepuesto al del pasillo acodado inferior, como consecuencia de la reforma de las termas. Entre ambos mediaba un relleno de $15 \mathrm{~cm}$. de grosor, constituido por una capa de tierra asentada sobre otra de cal.

Las únicas referencias bibliográficas a este mosaico corresponden a Belda (1947, 181-183, figs. 24, 4; 33, 1-2 y lám. LXX, 3) y a Lafuente (1959, 69, no 168, lám. XXVI1).

El motivo de la orla, que aparece en numerosos casos, es la representación estilizada de una arcada. A menudo se combina con florecillas en aspa que rellenan los espacios interme-

(15) Blázquez-González Navarrete, 1974, 429-432; Balil, 1965 a, 284-285). 


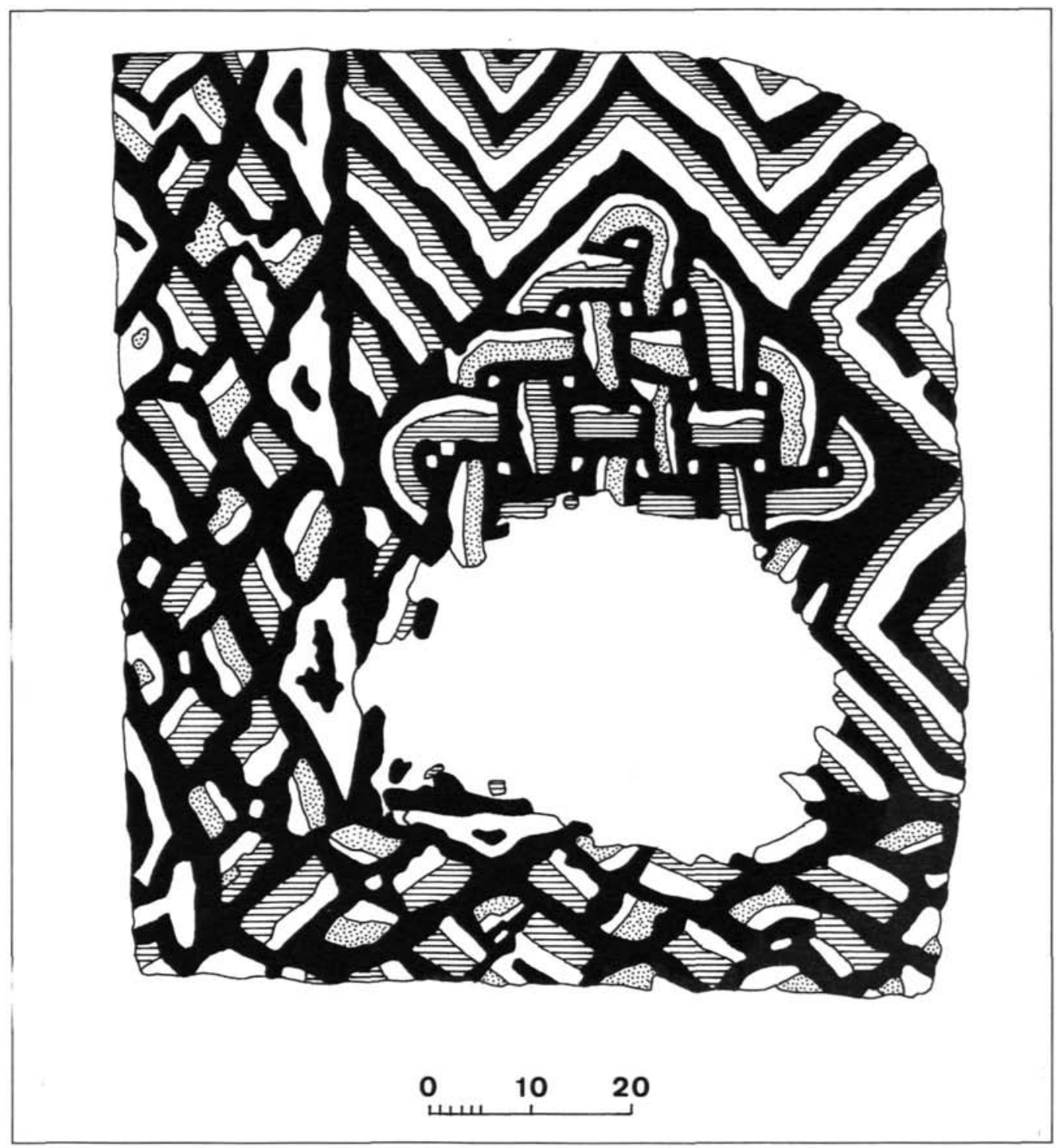

\section{Figura 5}

dios, así como con un remate en forma de hoja de hiedra (16), normalmente estilizada en triángulo. No hemos documentado un uso distinto al de orla, tanto para mosaicos geométricos como figurados.

(16) Las hojas de hiedra son comunes en los mosaicos tardíos de la Península Ibérica, según Fernández-Galiano $(1987,62)$. 
Con frecuencia los semicírculos se dibujan mediante el contraste de superficies cromáticas (17). Su trazado lineal parece una variante tardía -no atestiguada en mosaicos bícromos de tradición itálica- que se utilizó especialmente en los siglos III (sobre todo a partir de su segunda mitad en la Península Ibérica) y IV (18).

La pelta es uno de los motivos más antiguos del repertorio del mosaico ornamental romano. Aparece en el s. I d. C. (Balil, 1962, 54-56), durante el cual se utiliza preferentemente como un elemento aislado, por lo general decorando orlas, umbrales o como motivo "de relleno". Es a lo largo del s. II cuando, gracias a su geometrismo y a su gran simplicidad, se desarrollan claramente distintas combinaciones, articulándose entre sí o con otros elementos, que se utilizan en lienzos en los que constituyen el único motivo decorativo. Algunas de estas combinaciones se repiten insistentemente en numerosísimos mosaicos, y entre ellas la del pavimento que nos ocupa (AIEMA 455), bastante abundante en la musivaria hispana (Balil, 1962, 54-56). Las mismas geometría y simplicidad favorecen su utilización tanto en orlas como en fondos, o bien en paneles formando parte de una composición, e incluso decorando la totalidad del campo.

Picard (1949, 175, nos. 3 y 4) apreció un valor profiláctico en este elemento (19), frecuentemente combinado con otras filacterias, como las hojas de hiedra, cual es el caso de Torre-la Cruz.

La pelta es un motivo muy empleado en Africa, donde supone un elemento que, proveniente de la tradición itálica, se hace menos frecuente en baja época, apareciendo muy raramente en los siglos III y IV (Picard, 1949, 117 y 175-176). Por otra parte, aunque se considera como uno de los motivos más repetidos en los mosaicos italianos del s. II d. C., aquellos paneles o mosaicos completos en los que constituye el único elemento decorativo no son tan numerosos, faltando incluso en Ostia o Roma. Sin embargo sí se conocen en otros lugares de Italia y en Corinto, Tipasa o Susa, y están atestiguados en general en todas las provincias occidentales (20). En el s. IV no es, todavía, un hecho infrecuente, como demuestra un ejemplar de Maguncia (Parlasca, 1959, fig. 92), varios de Tréveris y otros ingleses y franceses (Mondelo, 1985, 130), junto a varios hispanos, como se verá más adelante. Se documenta, posteriormente, en un mosaico cristiano de Aquileia (Brusin, 1961, 30); a principios del s. V aparece en otro mosaico cristiano de Grado, y tenemos un ejemplar de Yugoslavia fechable en el s. VI (Mano-Zissi, 1965, fig. 28).

Las peltas entrelazadas son un tema atestiguado en todo el Imperio. A los lugares citados se podría añadir Heraklea, Lynkestis o Thysdrus entre otros (21) y perdura hasta fechas tan tardías como la segunda mitad del s. V en la basílica de Hermíone (Blázquez, 1982 b, 29-30). Según A. Balil, a partir de finales del s. II esta composición se usó especialmente en orlas. Lo que sí es cierto es que se puede observar su utilización preferente en lienzos rectangulares de mayor o menor longitud, ya sean orlas, paneles o campos, pues resulta un tema de fácil acomodo a este tipo de superficies, cual es el caso que nos ocupa (22).

(17) Existen ejemplos bícromos en Pompeya (Spinazzola, 1953, 300, fig. 337; 309-310, figs. 349-351).

(18) Vid. Blanco, 1978 a, 51-52, n 64, fig. 5, lám. 94 b; Blanco, 1978 b, 53-54, n 4, lám. 76; Mondelo, 1985, 107-141, no 8, fig. 10; 107-111, nº 1; Blázquez et al., 1989, 36-37, n 17, fig. 17; Blázquez-Ortego, 1983, nos. 55, 60, 63 y 66; Taracena, 1941, 59-60, fig. 9 .

(19) Sobre este aspecto cf. Germain, 1969, 117, $\mathrm{n}^{\circ} 178$.

(20) Cf. Balil, 1962, 55-56. Aparece también en áreas marginales de la Península Ibérica, como en Asturias (Fernández Ochoa, 1982, 360-364).

(21) Cf. Mondelo-Torres, 1985, 47. Mondelo $(1985,130)$ cita varios ejemplos de Europa Occidental.

(22) Balil y Mondelo (Balil-Mondelo, 1985, 256) han señalado la abundancia del tema en la Hispania Citerior, frente a su mínima representación en Andalucía. 


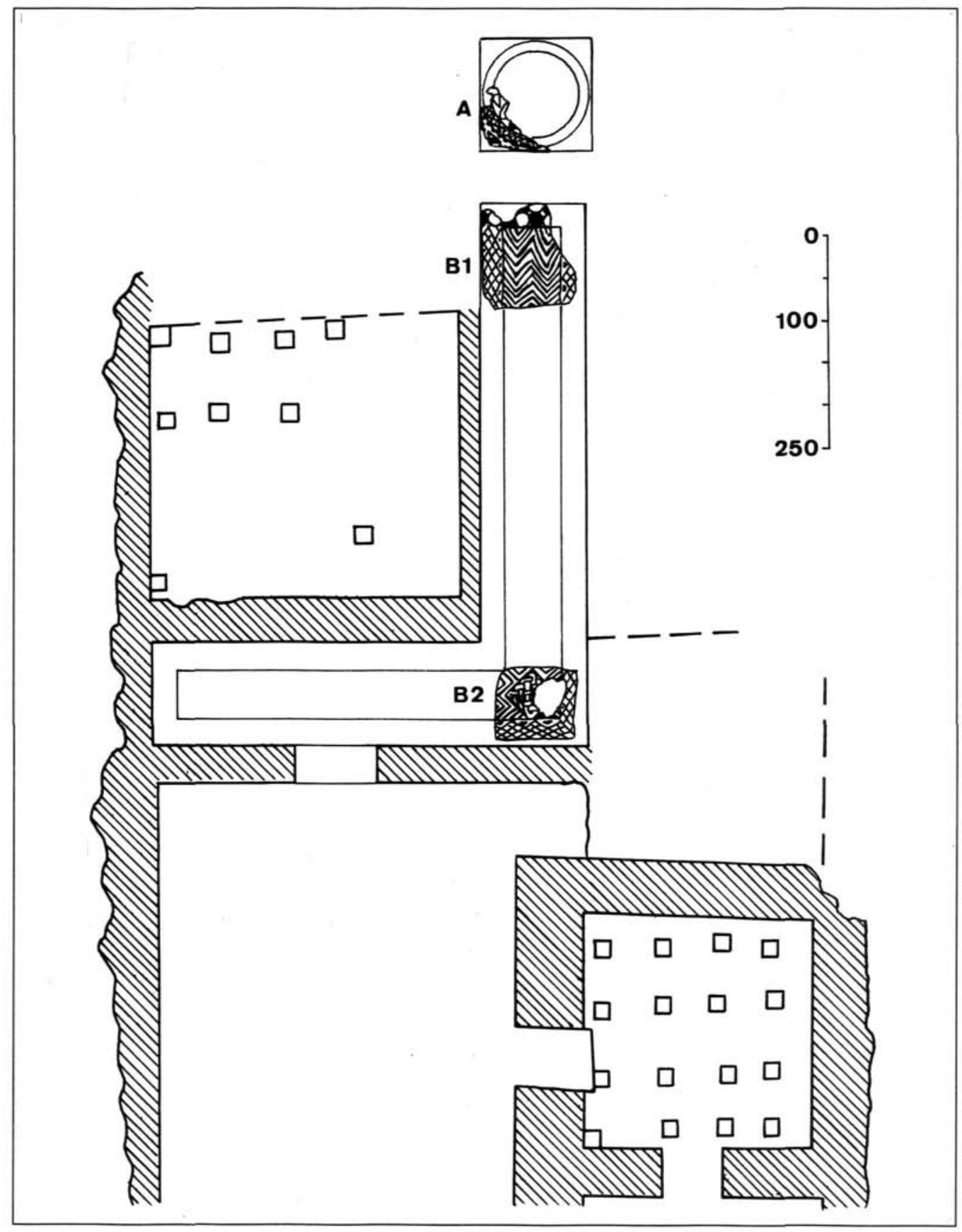

Figura 6 
Hay una serie de mosaicos hispanos, si bien minoritaria, en los que este tema se constituye en el único motivo del campo, como ocurre en nuestro caso. Contamos tanto con ejemplos de peltas bícromas (23), de los siglos II y III, como polícromas (24). Estas se documentan a partir de finales del s. II o comienzos del siguiente, tanto en la Península como fuera de ella, para predominar a partir de mediados del s. III y hasta el s. IV, después del cual el motivo cayó en desuso, si bien es verdad que ya se había hecho algo menos frecuente desde época tardoseveriana o postseveriana (25).

Un segundo grupo, ciertamente numeroso, lo constituyen aquéllos en los que el tema sirve de orla o fondo para un tapiz central (26). Sin embargo, quizá la mayor parte de los casos nos ofrecen un empleo del motivo en lienzos residuales de la composición mosástica, rellenando espacios adyacentes al campo principal o a los motivos principales de éste, o incluso alguno de los paneles rectangulares que forman parte de un mosaico geométrico (27).

En cuanto al remate central de las peltas, sus distintas variedades no parecen servir como índice cronológico claro. No obstante, puede afirmarse que durante el s. II y comienzos del s. III suelen estar ausentes, mientras a lo largo de la primera mitad de esta centuria se harán cada vez más frecuentes, por lo común en forma de triángulo, para generalizarse a partir de momentos avanzados de aquel mismo siglo, adquiriendo una mayor variedad formal (en triángulo, doble triángulo, puntos, hoja de hiedra, etc.) (Mondelo, 1985, 130-131).

De entre los mosaicos que presentan en su campo como único motivo el de las peltas afrontadas (AIEMA 455), los pertenecientes a conjuntos totalmente bícromos abarcan un lapso temporal que podemos ubicar en el s. II y la primera mitad del s. III. En estos conjuntos de tradición itálica, el tema que nos ocupa raramente se utiliza en espacios residuales, como orlas, fondos o paneles secundarios. Por otra parte, el mismo motivo, pero formado por peltas polícromas, lo encontramos abundantemente representado tanto como único tema del campo como en los espacios residuales a los que antes nos referíamos. Sin embargo, existe una solución que supone, en nuestra opinión, la transición entre ambas modalidades. Se trata de numerosos casos en los que, dentro de un conjunto mosaístico decididamente polícromo, se integra algunos espacios con peltas afrontadas monócromas. Ello supone un cierto arcaísmo, como hemos señalado más arriba, que hemos constatado para la segunda mitad del s. II y la primera mitad del III, es

(23) Vid. Balil, 1962, 54-56, fig. 5; Balil, 1970, fig. 1, lám. II; Barral, 1978, 54-56, n² 21, figs. XXII y XXIII; Blázquez, 1981, 99, n 70, mosaico C, lám. 77. Se conoce también varios ejemplos bícromos de la Gallia Belgica y de Germania (v. g., Parlasca, 1959, fig. 6, 3).

(24) Vid. Blázquez, 1982 b, 47, nº 34, fig. 23; Fernández Castro, 1978; Blanco, 1978 a, 27, nº 2, lám. 2; Blázquez-Ortego, 1983, nos. 55, 62, 63 y 72 o Germain, 1969, nº 178, lám. LIX, entre otros.

(25) Cf. Mondelo, 1985, 130-131; Balil-Mondelo, 1985, 255-256.

(26) Vid. Blanco, 1978 b, 26-27, nº 2, lám. 8 o Blázquez, 1981, 38-39, n 20, lám. 24, ambos con peltas bícromas. Peltas polícromas se pueden apreciar en: García Guinea, 1982, mosaico n 3, habitación 20; Sánchez Real, 1949, 224, mosaico II, fig. 2, láms. I, 2 y II, 1). Parlasca (1959) cita varias orlas de mosaicos polícromos alemanes que utilizan, en su mayor parte, peltas bícromas.

(27) Un ejemplo bícromo de finales del S. I o S. II en Póvoa de Cós (Nóbrega, 1951, 143-149, fig. 1, láms. I y II). Otros mosaicos polícromos de los siglos II y III conservan la bicromía en el motivo de las peltas (vid. Nieto Gallo, 1943; Blanco, 1978 a, 42, no 32, lám. 63 b); Blázquez, 1981, 24-25, n 8, fig. 1, lám. 10; Blasco, 1971, 719-726). Peltas polícromas pueden apreciarse en: Blanco, 1978, 40-41, n 25, fig. 7, lám. 51; Blázquez, 1982 b, 29-30, nos. 13 y 24, figs 19 y 20; Balil-Mañanes, 1980, 133 ss., fig. 2-3; Fernández Castro, 1982, 72, fig. 41 o Blázquez, 1982 b, nº 27, 1, láms. 24-33). Un ejemplo de Antioquía en Levi, 1947, 186-190, lám. XLII a. 


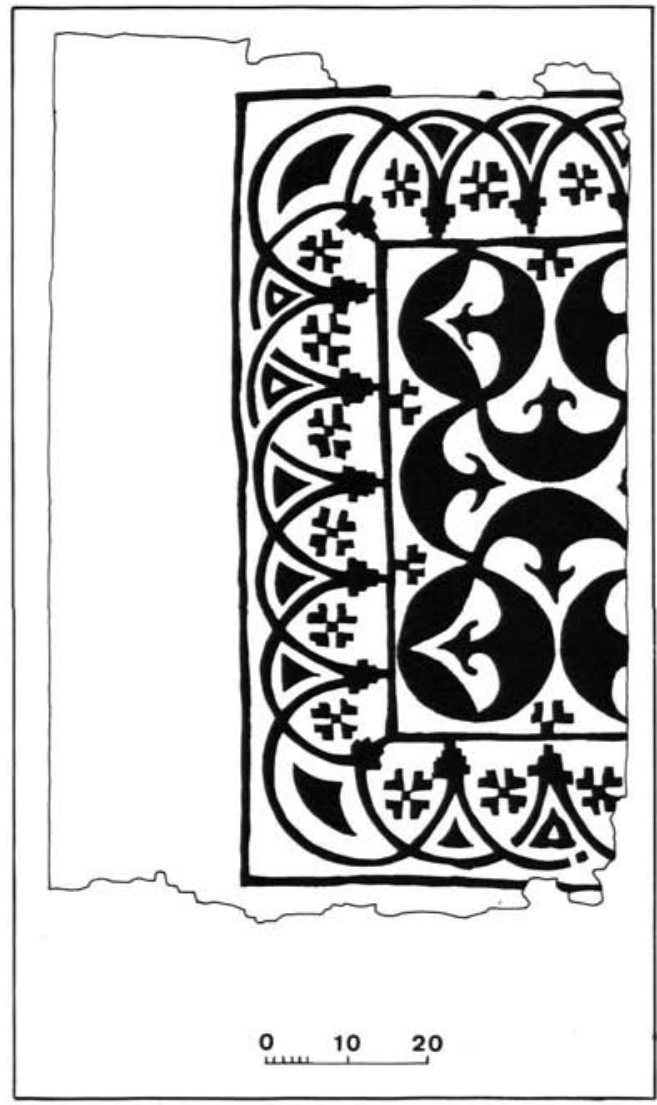

Figura 7

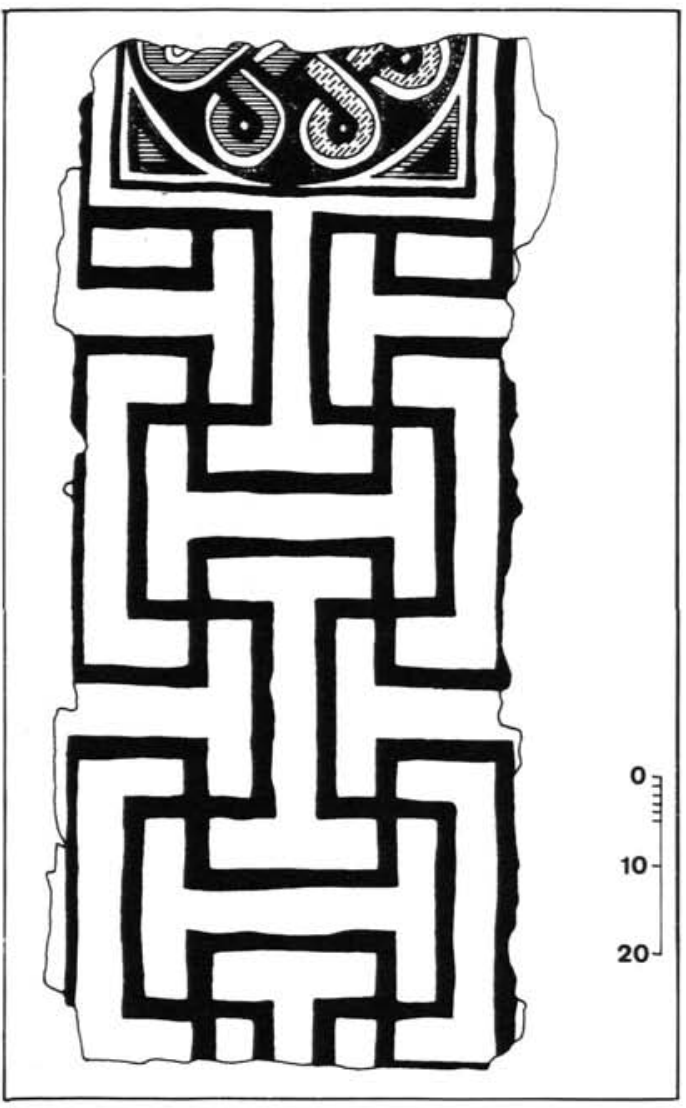

Figura 8

decir, durante los momentos transitorios entre los dos estilos antes citados. En estos casos se aprecia un predominio claro de la utilización del tema en espacios secundarios, sin que hayamos podido recoger, hasta el momento, ejemplo alguno en el que ocupe todo un campo mosaístico, aparte del de Torre-la Cruz. ¿A qué puede deberse este hecho? Parece claro que con la introducción de la policromía en el mosaico a partir de mediados del s. II, debido a influencias norteafricanas, gran parte del repertorio ornamental y compositivo propio de este área del Imperio pasa a caracterizar paulatinamente a los pavimentos elaborados en el resto de las provincias. Se ha propuesto la existencia de talleres que, fieles a una u otra tradición (la itálica, bícroma, y la norteafricana, polícroma), rivalizaron fuertemente por mantener o imponer, respectivamente, sus estilos. Sin menospreciar esta teoría, creemos que quizás podría contemplarse una parte del problema desde otra perspectiva, ya que se constata un porcentaje significativo de conjuntos que, a pesar de caracterizarse por una policromía no pocas veces profusa, recogen en algunos de sus espacios secundarios (muy propios de la compartimentación que caracteriza al estilo norteafricano), ya sean orlas, fondos o paneles, elementos provenientes de la tradición itálica, cuya bicromía se respeta durante un cierto tiempo (al menos hasta mediados del s. III). A la inversa, nos encontramos igualmente con algunos conjuntos esencialmente bícromos en los que se introduce 
ciertas notas de color, para adecuarse así a las nuevas exigencias del mercado. El hecho de que no hayamos documentado ejemplo alguno (salvo el de Torre-la Cruz) de conjunto polícromo en el que se reserve un campo completo al motivo de peltas monócromas puede deberse a que la policromía dominante ocupa generalmente esos espacios principales, destinando únicamente algunos paneles secundarios a los motivos bícromos.

La total bicromía del pavimento que nos ocupa, que caracteriza tanto al campo como a la orla, encaja mejor con los ejemplos situados en el s. II y la primera mitad del siguiente. El motivo de la orla y el remate de las peltas aconsejan una fecha avanzada dentro de esta misma centuria. En definitiva, creemos que una datación en el segundo o tercer cuarto del s. III convendría a esta pieza, considerada aisladamente. Nos encontraríamos, así, ante una de las últimas representaciones de peltas bícromas, e incluso con un ejemplar tardío de mosaico bícromo, en un momento en el que por doquier triunfaba la policromía, siquiera en pequeños detalles. Por el contrario, este pavimento permanece fiel a la tradición itálica, ya en desuso. Los mismos motivos que lo componen (peltas, semicírculos entrecruzados) son de origen itálico, si bien representan tipos evolucionados (peltas contrapuestas con remates, semicírculos trazados).

\section{Mosaico del apodyterium (Figs. 8 a 12)}

El mosaico que estudiamos a continuación pavimentaba una estancia rectangular, de aproximadamente 5.25 por $4.28 \mathrm{~m}$., identificable con el apodyterium de estas termas. Conservamos cinco fragmentos de la orla exterior. Los tres primeros (D 1, D 2, D 3) fueron donados por $\mathrm{D}^{\mathrm{a}}$. Aurora Silvestre Boronat, en 1975, al Museo de Villajoyosa. El cuarto fragmento (D 4) fue levantado del ángulo $\mathrm{N}$ de la habitación por D. José Payá Nicolau entre Febrero y Marzo de 1978, con permiso de los propietarios de la finca. El último de ellos se conserva, como hemos anotado anteriormente, en un domicilio particular de la ciudad.

Se trata de un mosaico polícromo. Teselas de $1 \mathrm{~cm}^{2}$ por término medio. Teselas por $\mathrm{dm}^{2}$ : aprox. 62. Materiales empleados: mármol blanco y negro, fragmentos de ladrillo (color rojo) y vidrio (color azul turquesa). Desconocemos el cromatismo del segmento D 5.

D 1. Fragmento de la orla exterior. Dimensiones máximas conservadas: anchura $56.5 \mathrm{~cm}$.; longitud $117.5 \mathrm{~cm}$. Motivo de meandros de dos teselas determinando paletones de llave de cuatro teselas, alternativamente dobles verticales y simples horizontales (AIEMA 267) (28). En uno de sus extremos este motivo enmarca un cuadrado, del que se conserva algo menos de la mitad, cuyo lado mide $41 \mathrm{~cm}$. Inscrito en éste, un círculo (AIEMA 543) con motivo de lacería de dos cabos (AIEMA 59). El círculo determina triángulos de hipotenusa curvilínea en las esquinas del cuadrado, ocupados por triángulos inscritos (Fig. 8).

D 2. Fragmento de la misma orla. Dimensiones máximas conservadas: anchura $54.5 \mathrm{~cm}$; longitud $99.5 \mathrm{~cm}$. Muestra, en el lado interior, algunos restos de la cenefa que rodeaba el campo decorativo, posiblemente similar a la del mosaico C (vid. supra) (Fig. 9, 3).

D 3. Fragmento de la misma orla. Dimensiones máximas: anchura $50 \mathrm{~cm}$.; longitud 92.5 $\mathrm{cm}$. El motivo enmarca un paralelepípedo casi cuadrangular de 42.5 por $41.5 \mathrm{~cm}$., que inscribe un cuadrado (AIEMA 545) con motivo de lacería de tres cabos (AIEMA 58). Los triángulos de las esquinas están ocupados por otros inscritos. Del lado en el que no aparece el motivo de meandros, tenemos una banda blanca de la que se conserva un ancho de cinco teselas, que nos

(28) Algunos autores los denominan "meandros de esvásticas en doble paletón de llave". 


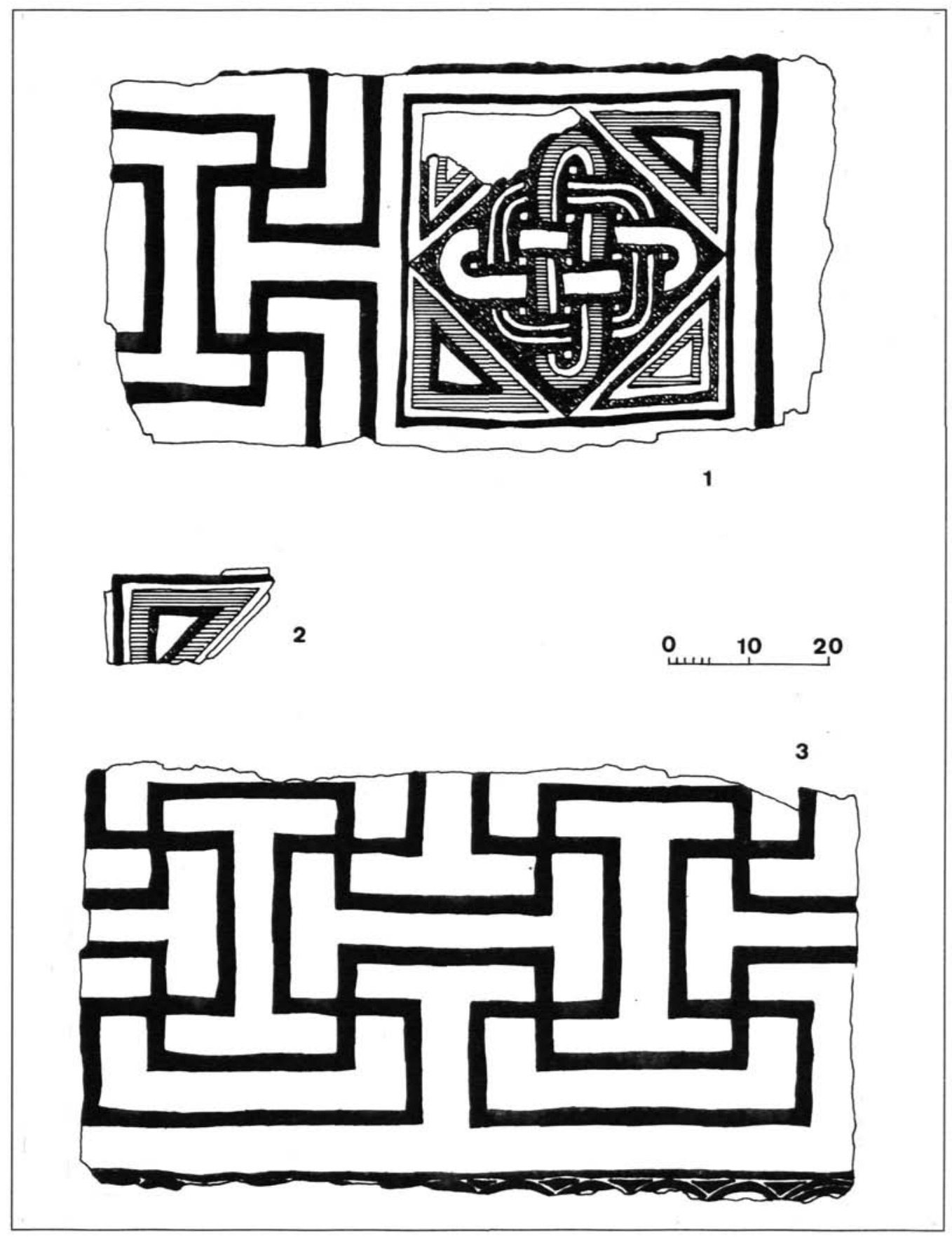

Figura 9 
indica la situación del cuadrado polícromo en una de las esquinas de la estancia (Fig. 9, 1).

D 4. Fragmento de un motivo de triángulos concéntricos idéntico a uno de los que nos muestra el fragmento D 3. Creemos, por tanto, que se trata de parte de un cuadrado similar al anterior (Fig. 9, 2).

D 5. Panel rectangular, con toda probabilidad incluido en la orla del mosaico, ante el umbral de la puerta SE. Dimensiones máximas aproximadas: anchura $57 \mathrm{~cm}$.; longitud $125 \mathrm{~cm}$. Queremos señalar que la descripción que ofrecemos a continuación se ha realizado a partir de la fotografía en blanco y negro publicada por Belda (1947, lám. LXIX, 2) (Fig. 10), por lo que tiene un valor provisional (29). Presenta un marco exterior similar a los de los cuadrados de los fragmentos D 1 y D 2, a saber: un filete negro doble, interrumpido en ambos extremos del lienzo conservado, pero que presumiblemente enlazaría con el motivo de meandros. Al interior nos encontramos con un filete blanco doble, seguido de otro negro simple, que constituye el marco propiamente dicho. El panel ornamental dispuesto en su interior se desarrolla sobre fondo blanco. En él encontramos un marco rectangular de filete doble realizado en un color indeterminado, que describe en el centro de los lados menores (ribeteados al exterior por otro filete negro) sendas semicircunferencias hacia el exterior. El espacio interior de estas semicircunferencias lo ocupan sendas veneras, trazadas en negro. En el lienzo rectangular resultante se pueden apreciar cinco peces dispuestos transversalmente, paralelos entre sí, mirando alternativamente hacia un lado y hacia otro. Representan de forma naturalista distintas especies. Tanto sus perfiles como sus principales rasgos anatómicos (aletas, ojo, boca, branquias) están silueteados mediante trazos simples, probablemente negros en la mayoría de los casos, rellenándose el resto de diversos colores. El movimiento de la superficie marina se representa mediante cortos trazos negros simples, algunos de ellos combinados con otros perpendiculares. Fuera de este marco, en los extremos del panel, se representan sendas plantas en flor (Fig. 10).

D 1, D 2, D 3 y D 4 son inéditos. Las únicas noticias de que disponemos sobre este mosaico nos las transmite J. Belda $(1947,175-177 ; 1946,144)$. En sus publicaciones no presenta dibujo o fotografía algunos de los mismos -salvo el panel con representación de peces-, por lo que cuando comenzamos nuestro trabajo se desconocía su paradero. Tras un estudio detenido nos hallamos en condiciones de afirmar que los fragmentos que presentamos como D 1-2-3-4 pertenecen, junto al D 5, a la orla que menciona aquel autor (Figs. 11 y 12). Por un lado, el motivo de meandros en doble paletón de llave inscribiendo cuadrados es propio de una orla, como demuestra el resto de cenefa, que rodearía el campo, conservado en D 2. Por otra parte, en orlas decoradas con este motivo (AIEMA 267), los cuadrados se suelen colocar en los ángulos de la estancia, constituyendo la transición de una pared a otra, como sucede en nuestro caso (Fig. 11). Belda comenta, además, que los siete fragmentos del mosaico levantados en 1926 (tres de los cuales suponemos que son los que denominamos D 1, D 2 y D 3), correspondían al "sector recayente al ángulo Nordeste", por lo que con toda probabilidad se puede identificar con éste al fragmento D 3 .

El motivo AIEMA 543, atestiguado en D 1, se dispondría a intervalos regulares, en número que desconocemos (no más de dos por pared), a lo largo de la orla. A juzgar por los paralelos conocidos, no es probable alternase con otros motivos.

(29) Nada se supo de este panel a partir de entonces. Por este mismo autor se conocía su disposición original "junto al umbral de la puerta recayente al pasillo". 


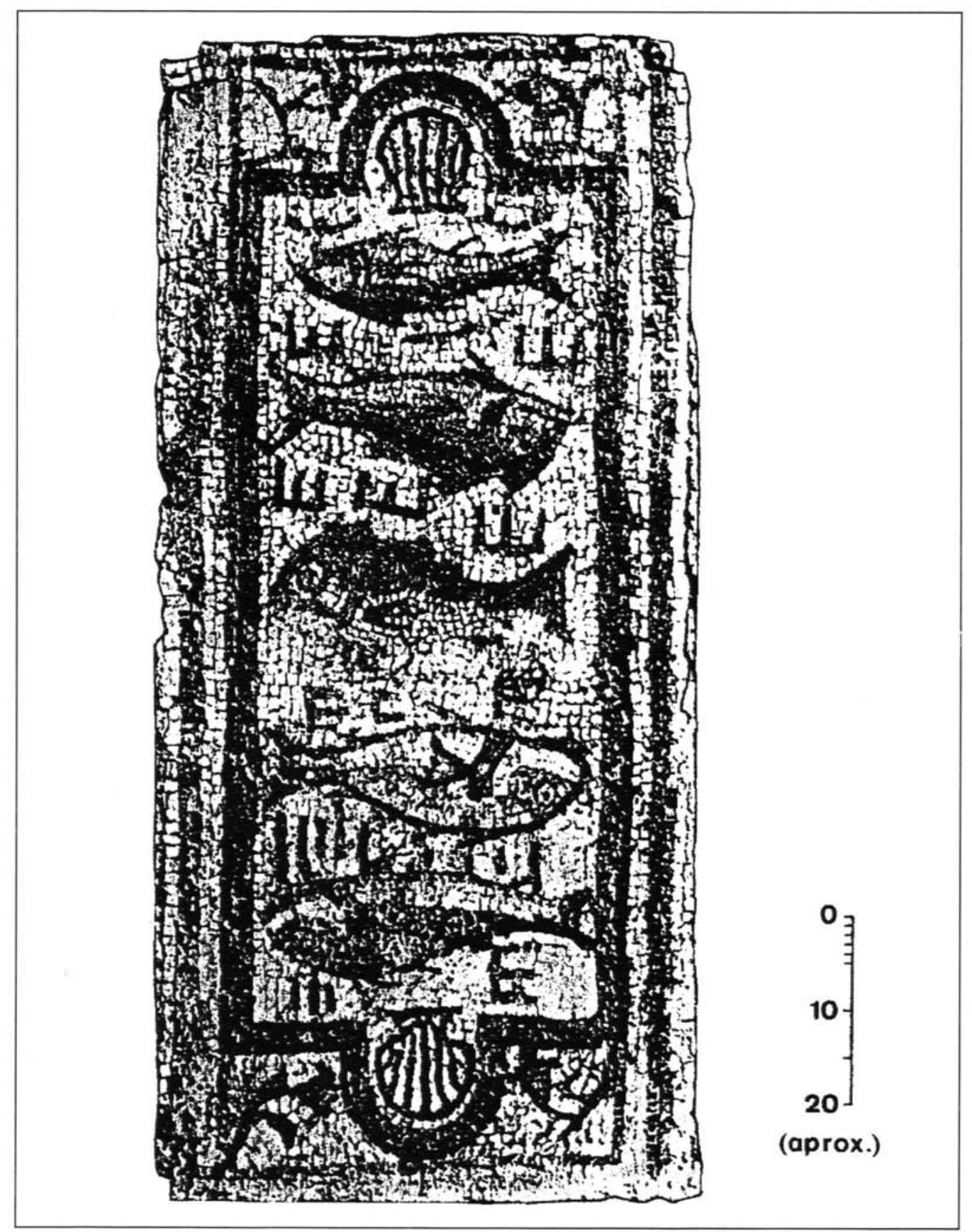

Figura 10 
Belda afirma, igualmente, que "el gran marco de dicho mosaico, en su sector recayente al ángulo Nordeste, parmaneció intacto hasta 1926", fecha en la que D. Jaime Silvestre lo levantó, enmarcándolo en siete rectángulos de hierro que se depositaron en un chalet de las afueras de la ciudad. Los fragmentos donados por su hija, Da ${ }^{a}$ Aurora Silvestre, al Museo en 1975, están, efectivamente, enmarcados por una lista de hierro. Por otra parte, Belda afirma que la parte conservada permite la reconstrucción ideal de toda la cenefa, que predominan las teselas blancas y negras sobre otras mucho menos numerosas de varios colores, y que destacan los "meandri" entrecruzados formando esvásticas. Todas estas características encajan a la perfección con los fragmentos que estudiamos (30).

Contamos con numerosos paralelos para el tema de meandros de paletones, tanto en la Península Ibérica como fuera de ella. Se trata de un motivo de origen itálico, documentado ya en Pompeya (Blake, 1930, 107, n 99, láms. 27, 1 y 3) y en un mosaico de Fishbourne, de época flavia (Cunliffe, 1971, 80, Fig. 17). En un primer momento parece utilizarse preferentemente extendido por todo el pavimento (Ramallo, 1985, 151; Santa María-Morricone, 1975, 50 ss., nº 39, láms. VII, LIV y LV; Prudhomme, 1975, 34 ss., lám. CLXV, 1).

El motivo se difunde, principalmente durante los ss. II y III, al resto de provincias del Imperio, especialmente las occidentales situadas al norte del Mediterráneo (31) -aunque también es muy del gusto de los talleres africanos-, para perdurar claramente en el s. IV (Mingazzini, 1966, 41). En este lapso de tiempo su uso principal se da en las orlas, tanto de mosaicos bícromos como policromos (32).

En Hispania es utilizado fundamentalmente por talleres bajoimperiales. Se desarrolla preferentemente en orlas, desde finales del s. II y sobre todo en los ss. III y IV, asociado invariablemente a campos polícromos de tipo geométrico (Ramallo, 1985, 131), y combinado las más de las veces con cuadrados polícromos que encierran decoración geométrica, como en nuestro mosaico, o figurada. Aunque lo habitual en otras zonas del Imperio es dibujar los meandros mediante filetes, cual es nuestro caso, en la Península Ibérica predominan los ejemplos realizados con trenza, normalmente de dos cabos (Mondelo, 1985).

La variante que combina los meandros de paletones con cuadrados se constata ya en pavimentos bícromos, como el hallado en la Huerta de Otero (Mérida), fechado a finales del s. II o comienzos del siguiente (Blanco, 1878 a, 49 , n 56 , láms. 87 b y 88 a).

Más abundantes son los ejemplos pertenecientes a mosaicos polícromos, bien representados en Elche durante el s. IV, tanto en orlas como en campos. Así lo tenemos en algunos pavimentos

(30) J. Payá extrajo unas tallas en yeso de la pared correspondiente al ángulo en el que se encontraba el fragmento de mosaico D 4. Se trata de las mismas que aparecen en una fotografia del ángulo $\mathrm{N}$ del apodyterium publicada por Belda (1947, lám. LXX, 1), lo que confirma nuestra hipótesis.

(31) Durante el s. II aparece tanto en mosaicos galos, combinado a menudo con florones polícromos (vid.Stern, 1967, n 45, lám. XXIV), o incluso rellenando casetones (v. g. Lancha, 1977, 113, fig. 58), como en algunos británicos, que presentan un relleno de florones y motivos figurados (Smith, 1975, 275, lám. CXIV).

(32) Conocemos distintos ejemplos de orlas decoradas con meandros de paletones que no se combinan con cuadrados (vid. Ramallo, 1985, no 118, fig. 30, láms. LXXIV-LXXVII; Blázquez, 1982 a, nos. 30 y 67, fig. 7 y lám. 26; Blanco, 1978 b, 53-54, n 41, lám. 76; Balil-Mañanes, 1980, 5-16, fig. 1, lám. 1; Balil, 1979, 19-30, láms. I-V; Fernández Castro, 1978, 221, fig. 13; García Merino, 1971, 86, fig. 5; Lavagne, 1979, 85-87, nº 89, láms. XXIV-XXV; Lancha, 1977, 98, fig. 50 bis, entre otros). 


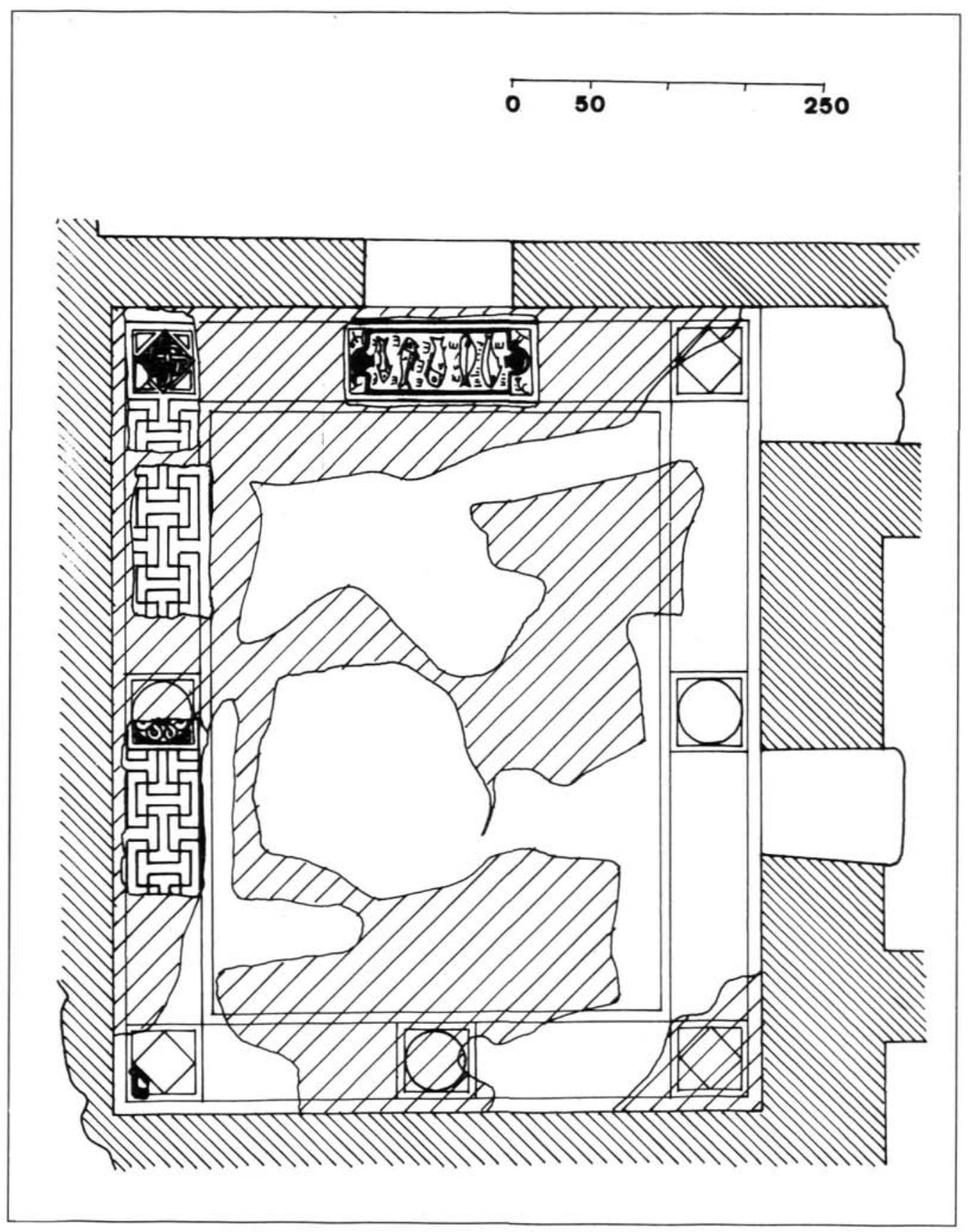

Figura 11 
de la villa de Algorós (33) o en la orla sur de la basílica paleocristiana (Palol, 1967, 201 ss., fig. 73). Otro paralelo, aunque esta vez ocupando, en sucesivos registros, el campo del pavimento de un peristilo, se localiza en la villa de El Palmeral del Portus Illicitanus (Santa Pola), fechable en la primera mitad del s. IV (34).

En la villa de Los Cipreses, de Jumilla, la orla de un mosaico datado a finales del s. III o durante el s. IV presenta igualmente este motivo (Ramallo, 1985, 128-132, $\mathrm{n}^{\circ} 108$, fig. 22). Lo encontramos también en otra orla de la villa del Camino Viejo de las Sepulturas de Balazote (35).

Otros claros paralelos, de época severiana, encontramos en Volúbilis (Thouvenot, 1948, 69, lám. II; Thouvenot-Luquet, 1951, 91-92, fig. 1, lám. XXI) y en Cirene (Mingazzini, 1966, 41). No faltan ejemplos, más tardíos, en el área griega (Pelekanidis, 1974, 51, lám. 15).

Por lo que respecta al tema ictiográfico, su aparición en la musivaria de tradición italo-helenística se encuentra en estrecha relación con la temática de la pintura mural campana del momento. Dentro de esta tendencia tenemos una serie de mosaicos hispanos con representación de peces en rica policromía, con un tratamiento pictórico conseguido mediante pequeñas teselas. Corresponden principalmente a termas y estanques datables hasta finales del s. I a. C. (Fernández-Galiano, 1984, 102; Balil, 1960; Blázquez, 1982 b, 36).

Con la generalización de la técnica blanquinegra en los mosaicos de tema marino de la zona de Roma se produce, forzosamente, una adaptación a ella (Beccati, 1961). Estos cambios influirán decisivamente en el desarrollo posterior del tema en otras provincias del Imperio. En primer lugar, las composiciones cubren superficies mucho mayores, perdiendo el detallismo pictórico de los ejemplares precedentes. Sin embargo, se trató de mantener parte del efecto ilusionista y la representación naturalista de la fauna marina, factores que dotaban al tema de un especial interés. Esto fue sólo en parte posible, ya que la bicromía reducía grandemente los recursos del mosaísta, que se veía forzado en la mayor parte de los casos a representar un número muy limitado de especies de silueta bien distintiva. La plenitud de la técnica blanquinegra se alcanza en Roma desde comienzos del s. II, a lo largo del cual se extenderá su influencia por las escuelas provinciales, especialmente por las occidentales del norte del Mediterráneo. Esta influencia lleva pareja un cierto -que no absoluto- abandono del tema ictiográfico en la mayoría de estas provincias (Fernández-Galiano, 1984, 104-105), con la excepción de Africa e Hispania.

La temática que nos ocupa constituye uno más de los aspectos que nos hablan de una intensa relación entre escuelas africanas e hispanas. Las primeras siguen, desde sus comienzos, el pictoricismo de la policromía, que facilitaba, indudablemente, la difusión del tema (36). De esta manera, el motivo se repetirá con mucha frecuencia en los mosaicos polícromos de los ss. II al IV, aunque sus orígenes en el s. II son mal conocidos. A veces la fauna marina se integra en escenas de pesca, pero al principio el motivo más importante continúa siendo la representación naturalista de las especies, mientras el resto de elementos revisten únicamente un carácter anec-

(33) Balil-Mondelo, 1985, 130-131, n 6, fig. 8 y 134-135, $n^{\circ}$ 8, fig. 10. En los nos. 1, 3 y 9 se puede apreciar un campo en el que el motivo de los meandros de paletón, realizados en trenza, enmarcan cuadrados con motivos geométricos.

(34) Sánchez Fernández-Blasco-Guardiola, 1986. Las monedas halladas se fechan desde $321 \mathrm{~d}$. C.

(35) Blázquez et al., 1989 b, n 34, fig. 11, lám. 30-31

(36) Sobre las razones de la abundancia del tema cf. Levi, 19477, 596. 


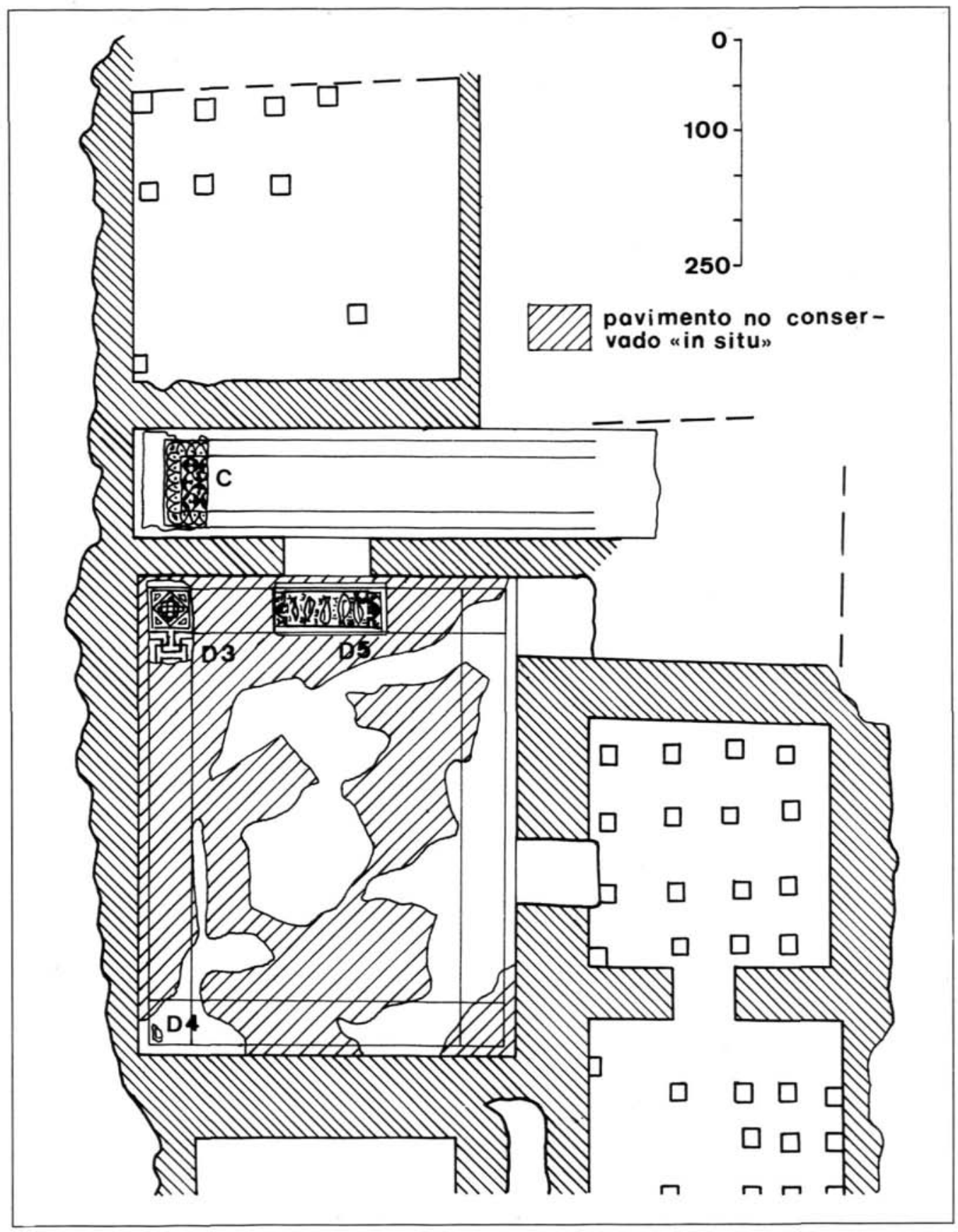

Figura 12 
dótico. Otras variedades consistirán en su integración en pavimentos con el tema del dios Océano y su séquito, o bien el del thyasos marino. El interés anatómico se irá perdiendo a partir de comienzos del s. IV, en favor de otros elementos (Fernández-Galiano, 1984, 104-105).

No se puede pasar por alto la estrecha vinculación de este repertorio con instalaciones termales, ninfeos, estanques, piletas, fuentes, etc., de acuerdo con una tendencia a la adaptación de la temática al uso, constante a lo largo del Imperio (37). Este hecho, que se constata también en Torre-la Cruz, constituye una de las causas fundamentales de la abundancia del tema (Levi, 1947, 596).

El tema ictiográfico se documenta en gran cantidad de mosaicos hispanos, sobre todo en los ss. III y IV. Al igual que hemos apuntado para el caso africano, también aquí tenemos una característica distintiva de los ejemplares del s. III: su centro de interés lo constituye precisamente la representación de especies marinas (38), destinada a animar al espectador a intentar su identificación. Este objetivo se consigue con la utilización de espacios geométricos neutros o repetitivos, preferentemente campos completos, frisos corridos o medallones (Fernández-Galiano, 1984, 107), que no distraen la atención. El ejemplar de Torre-la Cruz estaría a medio camino entre aquellas dos opciones, lo que constituye una cierta originalidad en el contexto de los mosaicos hispanos con representación de peces.

La existencia de una gran cantidad de mosaicos con este tema en todo el mundo romano hará que solamente nos fijemos en aquellos, preferentemente hispanos, que presenten algún paralelismo claro, limitándonos a citar algunos otros casos de interés (39). No entraremos en los ejemplos bícromos, sino que nos ceñiremos a los de técnica polícroma (40).

Hemos de detenernos, antes de aportar algunos paralelos, en el estilo con el que están representados los peces del panel que estudiamos. Destaca, en primer lugar, la evidente importancia del dibujo, realizado en trazo simple, probablemente negro en casi todos los casos, que diseña los detalles anatómicos de las figuras: silueta, aletas, branquias, ojo y boca. Rellenando la silueta se disponen, por zonas, diferentes colores, característicos de cada especie. El ojo se delinea mediante una simple tesela negra rodeada de un pequeño círculo blanco, circundado o no, a su vez, de otro de color distinto de este último. La representación, aunque sencilla, es marcadamente naturalista. No nos cabe duda de que se trata de especies reales -como es normal en los mosaicos romanos de tema ictiográfico-, aunque al desconocer su cromatismo la identificación de algunas de ellas se hace difícil, por lo que de momento no aventuraremos opinión alguna.

Se plasma los cinco peces desde un único punto de vista, es decir, de perfil, eludiendo cualquier afán tridimensional. Su disposición en el panel es rígidamente simétrica: miran alternati-

(37) Cf. Stern, 1959, 120 y DePuma, 1980, 72-79.

(38) Sobre las especies que suelen representarse cf. Balil, 1960, 284 y 292.

(39) Existen diversos trabajos que nombran gran cantidad de mosaicos con peces de las distintas zonas del Imperio. Citaremos, entre ellos, Balil-Mondelo, 1985, 254-256; Belz, 1980; Blázquez, 1982 b, $32-37$ y 1987; Blázquez et al., 1989 b; Fernández Galiano, 1984, 104-108; Foucher, 1960; Levi, 1947, 596-603; un completo catálogo en DePuma, 1980. El estudio del tema ha sido acometido en trabajos como: Levi, op. cit.; Gullini, 1956, 20-32; Balil, 1960, 267-310 y Beccati, 1961, 34 ss., entre otros.

(40) Sobre pavimentos bícromos hispanos con representación de peces cf. Fernández-Galiano, 1984, 107. Según A. Balil y R. Mondelo (Balil-Mondelo, 1985, 255, nota 13), los más antiguos de la serie serían uno de Elche y otro de Calpe. Sobre este último no hemos encontrado dato alguno en la bibliografia existente -fundamentalmente Cavanilles, 1797 (1943 y 1970) y Pellicer, 1965-, por lo que pensamos que se trata de una confusión. 
vamente en uno y otro sentido, aunque el ejemplar del centro se encuentra invertido respecto del resto. Estas últimas características dotan al pequeño panel de cierto dinamismo.

En lo que respecta a la representación de la superficie del agua, no se emplea un procedimiento único: tenemos cortos trazos curvados, otros rectilíneos -a veces dispuestos en paralelo- $y$, por último, algunos de éstos rematados en breves trazos perpendiculares, de donde resultan formas en " $U$ ", en " $F$ " o en " $E$ ". Todos ellos parecen realizados en trazo negro simple (41). Con esta casi abigarrada simulación de la superficie acuática se persigue, claramente, acentuar el movimiento de la composición, dando así la impresión de que los peces se encuentran en su medio natural, y evitando consiguientemente producir la imagen de una naturaleza muerta (42).

El paralelo geográficamente más próximo es un pavimento de Elche fechado desde época postseveriana hasta finales del tercer cuarto del s. III, que sólo conocemos por referencias (43), por lo que no podremos efectuar las oportunas comparaciones que, tanto por su proximidad geográfica como cronológica con el ejemplar de La Vila Joiosa, sin duda habrían sido muy reveladoras.

Por lo que respecta a la representación de los peces, hemos encontrado algunos ejemplos polícromos, fechados desde finales del s. II a comienzos del IV, que presentan unas características estilísticas similares a las enunciadas anteriormente (44). Otro tanto sucede con algunos pavimentos de la segunda mitad del s. III, y, sobre todo, del s. IV, caracterizados, sin embargo, por un mayor esquematismo de las figuras (45).

La problemática de la representación del agua carece de un estudio de conjunto, si bien diversos autores la han abordado puntualmente (46). El tratamiento tonal del agua en los mosaicos de tipo helenístico, derivado de las convenciones pictóricas propias de este arte, se apoyaba en la utilización de la línea. Sin embargo, este elemento sufre una evolución que lo convierte en simples trazos esquemáticos en época bajoimperial. Al mismo tiempo, de ser un componente meramente accesorio pasa a cobrar un cierto protagonismo, al emplearse para rellenar los espacios existentes entre figura y figura, casi siempre con un claro horror uacui (Fernández Galiano, 1984, 110). Mientras en los pavimentos bícromos apenas se representan algunas líneas

(41) Puede encontrarse paralelos hispanos de este motivo, fechados, en conjunto, entre el s. II y el IV, en:(41) Puede encontrarse paralelos hispanos de este motivo, fechados, en conjunto, entre el s. II y el IV, en:Blázquez, 1981, 19 ss., n 4, figs. 3-7, láms. 3-6; Blázquez, 1982 a, 49, n 56, lám. 87 b; García y Bellido, 1953, fig. 9.

(42) Sobre las representaciones de peces vivos, o bien de "pescados", en la musivaria romana, cf. Balil, 1960 y 1970.

(43) Según Palol $(1963,26)$ se hallaba inédito hasta entonces.

(44) Así sucede con mosaicos de Córdoba (Blázquez, 1981, 31-33, nº 14, fig. 13, lám. 18 b), Vilaseca (Tarragona) (Ventura Solsona, 1962, 42, fig. 57; Balil, 1965 b, 32-33; Bobadilla, 1969; Balil-Mondelo, 1985, 251-256, lám. I), Osuna (Sevilla) (Blázquez, 1982 a, 84, no 95, lám. 47), Mérida (García Sandoval, 1966, 42, nº 31, fig. 8, láms. 53 b-63 a; Blanco, 1978, n 31, lám. 59) y Toledo (Blázquez, 1982 b, 33-36, n 25, lám. 46; 47-48, láms. 20-23). Algunos casos, particularmente del s. III, representan la superficie acuática mediante largos trazos oscuros (vid. Blázquez, 1981, nº 8, láms. 20-27 y n 28, lám. 52,2; Blázquez et al., 1989 b, 40-42, nº 31, habitación XXXIII, fig. 8, láms. 12 y 23-27).

(45) Vid. García Guinea, 1982, n 3, fig. 25; Abasolo, 1983, habitación C, fig. 14, láms. III-XIII; BlázquezOrtego, 1983, n 48, láms. 22 y 38; Fernández-Galiano, 1984, 109-110, nº 138, fig. 3, láms. LXIV-LXVI; Blanco, 1978 a, 51, nº 62, lám. 93; Bonsor, 1931, 20, fig. X; Depuma 1980, vol. II, 143, n 117, fig. XCVI, 164.

(46) Clouzot, 1935, 230 ss.; Balil, 1961, 123 ss. o Picard, 1960, 46 ss. 
paralelas, llegándose incluso a dejar el fondo vacío en multitud de casos, con el uso de la policromía nos encontramos ante una gran variedad de procedimientos para dibujar la superficie acuática, algunos de los cuales caracterizan a determinadas zonas del Imperio durante determinadas épocas (47).

Las veneras que aparecen en el panel de Torre-la Cruz no son, por su parte, demasiado frecuentes en el repertorio del mosaico romano, ni aún en composiciones de tema marino. El paralelo más claro en lo que se refiere a su disposición a ambos lados de un panel rectangular es el de un pavimento de Jurançon, fechable probablemente en el s. III d.C. (Depuma, 1980, 106, nº 84, fig. 134, lám. LXX).

Tampoco es frecuente, en los ejemplos hispanos, la representación de elementos vegetales. En el caso que nos ocupa éstos aparecen en los cuatro ángulos del panel, en forma del mismo tipo de planta en flor. Pensamos que puede tratarse de una variedad de iridácea, quizás la Iris germánica, que es una flor de jardín (48).

Por lo que respecta al campo, propiamente dicho, del mosaico que nos ocupa, éste presentaba, según Belda, "motivos artísticos de condición análoga o similar a la de otros, tallados en los estucos murales". De acuerdo con los ejemplares que hemos citado, a la orla de meandros de paletones debería corresponder, con toda probabilidad, un campo de carácter geométrico. Esta es, precisamente, la decoración predominante en las tallas de yeso que se conservan en el Museo Arqueológico Provincial de Alicante, y que actualmente tenemos en estudio (49). Concretamente, sabemos que la parte inferior de las paredes de la sala que pavimentaba el mosaico que estudiamos estaba decorada con esvásticas enlazadas determinando espacios cuadrangulares ocupados por sendas flores tetra y octopétalas alternas. La esvástica, combinada o no para dar lugar a paletones, se documenta en el campo de algunos mosaicos orlados por meandros de paletones (50), en ocasiones determinando cuadrados decorados con motivos florales o geométricos, como hemos visto. No sería, pues, extraño que el campo de nuestro mosaico hubiese contado con una decoración de este tipo, hipótesis que quizá pueda comprobarse en el futuro tras una re-excavación de estas instalaciones termales.

En cuanto a la cronología que conviene a este pavimento, ya hemos observado anteriormente que la utilización como orla del tema de meandros de paletones enmarcando cuadrados tiene lugar, en Hispania, desde finales del s. II y durante los dos siguientes. Su representación mediante filetes negros parece documentarse hasta mediados del s. IV. Por otra parte, la cenefa de semicírculos entrecruzados trazados puede situarse a partir de un momento avanzado del s. III.

Por lo que se refiere al panel con representación de peces, el procedimiento empleado para representar las figuras en Torre-la Cruz es similar, como hemos visto, al de otros pavimentos fechados entre finales del s. II y el s. IV, aunque los mayores paralelismos podemos encontrarlos

(47) Acerca del N de Africa cf. Picard, 1960, 45-48. Sobre los talleres del NW hispano, centrados en la segunda mitad del s. III, cf. Acuña, 1972, 468 ss.; Acuña, 1973; Acuña, 1974, 22-27; Balil, 1973; Balil, 1975, 259 ss., láms. CIII-CVI; Blázquez, 1982 b, 37 y 38; Fernández-Galiano, 1984, 109. Algunos de éstos muestran un estilo similar al de Torre-la Cruz, por lo que respecta a la representación de los peces.

(48) Así parecen indicarlo la presencia de rizoma, las hojas simples y estrechas en disposición alterna o la inflorescencia en cima con flores del tipo de las iridáceas.

(49)Cf. Belda, 1946, 1947 y 1948.

(50) Vid. Ramallo, 1985, 108, fig. 22 o Mondelo, 1985, $\mathrm{n}^{\circ} 6$, fig. $8 \mathrm{y} \mathrm{n} \mathrm{n}^{\circ} 8$, fig. 10, entre otros. 
sin duda en diversos ejemplares del s. III. Por todo ello, creemos que este mosaico aporta unos márgenes cronológicos ubicables entre un momento avanzado y el fin del s. III.

\section{CONCLUSIONES}

No nos resta sino añadir algunas consideraciones de carácter global que, a su vez, constituyen una nueva interpretación del conjunto (51).

Uno de los aspectos más interesantes de la decoración mosaística de Torre-la Cruz es la coexistencia de tradiciones bícromas, de origen itálico, y polícromas, de raíz africana. Para empezar, nos encontramos con un nivel inferior del que conocemos, tan sólo, restos de dos pavimentos. De uno de ellos, que denominamos $\mathrm{A}$, apenas se conserva un ángulo de lo que sin duda es una roseta de triángulos curvilíneos. Se trata, como ya se ha dicho, de un motivo de marcado origen itálico. Tanto es así que, constatándose su práctica ausencia en pavimentos africanos, se ha utilizado como argumento para apoyar la revisión de la teoría del africanismo de los mosaicos hispanos. De hecho este tema conservará, en muchos casos, su bicromía durante la segunda mitad del s. II, e incluso los comienzos del siguiente, combinándose, como sucede en algunos ejemplos béticos, con detalles polícromos en las enjutas del cuadrado que lo inscribe, e incluso formando parte de conjuntos pavimentales de carácter polícromo. Sin embargo, como hemos visto, tampoco este tema consigue sustraerse a la tendencia general, y termina por dar ejemplos completamente polícromos a partir de comienzos del s. III, como sucede en nuestro caso.

El mosaico de chevrons, por su parte, presenta una clara influencia de las escuelas del norte de Africa, donde el tema se desarrolla especialmente a partir de época postseveriana, aunque se constatan varios ejemplos del s. II, sobre todo en su segunda mitad. También la orla contiene un marcado carácter tardío, de tradición norteafricana, a juzgar por los paralelos que conocemos. Por su parte, los motivos circulares de los extremos del pavimento, imitación grosera de opus sectile, son igualmente típicos de un momento bajoimperial, desarrollándose contemporáneamente en el Mediterráneo Occidental a partir del s. III.

Por lo que respecta al nivel superior de los baños, se nos ofrece una panorámica bastante distinta. Ante todo, llama poderosamente la atención la existencia de un pavimento totalmente bícromo superpuesto a los polícromos del nivel inferior. Hay que recordar, sin embargo, que aquél se inscribe en un conjunto dotado de policromía, como puede apreciarse en el apodyterium. Los elementos decorativos empleados en este nivel superior dejan ver, por lo que conocemos hasta la fecha, un gran peso específico de la tradición itálica, modificada por las nuevas tendencias polícromas. Así ocurre con los meandros de paletones, tema que se difunde posteriormente al resto de provincias del Imperio, especialmente las del Mediterráneo Occidental, o con las peltas, que raramente aparecen en pavimentos africanos a partir del s. III. El gusto por la policromía se manifiesta en el alarde colorístico de los cuadrados y rectángulos enmarcados por el sobrio motivo bícromo de los meandros de paletones. Pensamos que el esquema compositivo del campo debió estar muy compartimentado, como sucede en algunos ejemplares de las villas de l'Algorós, Los Torrejones o Los Cipreses orlados por meandros de paletones, en consonancia

(51) Los trabajos de Belda $(1946,1947$ y 1948) presentaban numerosas incorrecciones y deficiencias, que hacían necesaria una revisión. 
con el gusto de la tradición norteafricana por la fragmentación de las superficies. También parece responder a ella la representación naturalista de los peces.

A tenor de todo lo expuesto, podemos concluir que nos situamos en una época de coexistencia de ambas tendencias, la bícroma y la polícroma, que aprovechan mutuamente sus repertorios decorativos.

Algo similar sucede en el resto de Hispania, particularmente durante la primera mitad del s. III. En el área de Carthago Nova comienza a observarse desde mediados del s. II un proceso que se acentúa en la primera mitad del siguiente y, sobre todo, en el s. IV, de "ruralización" del mosaico, desplazándose la clientela hacia áreas distintas de los centros urbanos tradicionales. Según S. Ramallo (Ramallo, 1984, 27-28), paralelamente se inicia el desarrollo de la policromía extendida a grandes superficies. En un principio ésto sucede tímidamente, introduciendo pinceladas de color en los motivos más ricos del mosaico y, más tarde, extendiéndose a su totalidad.

En alguna medida, la técnica blanquinegra se mantiene claramente hasta, al menos, parte del s. III, conviviendo con las nuevas corrientes. A. Balil comenta, a propósito de esta coexistencia: "...la resistencia de los talleres bícromos nos parece, hoy, inmensa" (Balil, 1967, 544). Cuando conviven, según este autor, el mosaico bícromo se suele reservar a los ambientes más modestos o menos representativos: "Los hallazgos del s. III, en aquellos casos en que es posible conocer su disposición y situación en la economía de un conjunto arquitectónico, muestran su uso en locales o construcciones que ocupan un lugar secundario". Algo así se puede constatar en la Bética durante, particularmente, la época severiana. En el caso del nivel superior de los baños de Torre-la Cruz tenemos un ejemplo más: en efecto, advertimos que para el salón destinado a apodyterium (en cierto modo, la sala principal de unas pequeñas termas como éstas) se encarga un pavimento polícromo, mientras que para el pasillo que daba acceso a esta estancia (un lugar de paso, y por tanto secundario) no existe inconveniente en elegir una alfombra bícroma.

En los motivos decorativos del nivel inferior apreciamos, paradójicamente, un carácter más tardío. Son, probablemente, una obra de artesanos locales que remeda, de forma poco cuidada y con materiales de baja calidad, algunos temas decorativos en uso.

Para los mosaicos del nivel superior sí tenemos, sin embargo, algunos paralelos en la zona, en cuanto se refiere al repertorio y al estilo. Entre los más claros queremos citar los de: la villa de Los Cipreses (Jumilla, Murcia), datados a finales del s. III o en la primera mitad del s. IV; la villa de Los Torrejones (Yecla, Murcia), con una datación de la primera mitad del s. IV; la villa de l'Algorós (Elche), fechados en el s. IV (probablemente en su segunda mitad); la Basílica Paleoçristiana de Illici, de la segunda mitad del s. IV o la villa de El Palmeral, junto al Portus Illicitanus, con pavimentos datados en la primera mitad del s. IV.

En todos ellos nos encontramos con varios de los motivos que aparecen en la decoración mosaística del nivel superior de Torre-la Cruz. Particularmente se repite el tema de los meandros de paletones enmarcando cuadrados en los que se inscriben círculos u otros cuadrados con motivos de lacería: lo encontramos, sobre todo, en orlas (en la villa de El Palmeral decora el campo del corredor que rodea un patio, aunque su esquema básico coincide con el de La Vila Joiosa). Advertimos una gran similitud en la composición de los campos geométricos, en los que también abundan aquellos mismos cuadrados. Encontramos, asimismo, varios ejemplos de orla de semicírculos entrecruzados trazados. Más raro es el motivo de las peltas entrelazadas 
(AIEMA 455) (no así en otras combinaciones), que aparece solamente en un panel secundario de la villa de l'Algorós.

Por todo ello pensamos que, probablemente, los pavimentos citados fueron realizados por un mismo taller (52), que trabajaría en el SE de la Península, entre un momento indeterminado del s. III y, al menos, el s. IV, satisfaciendo fundamentalmente la gran demanda de las florecientes villae rústicas o, en menor grado, suburbanas (53). Será necesaria, sin embargo, la realización de estudios específicos al respecto, para confirmar o desmentir esta hipótesis. En cualquier caso, nos parece evidente la existencia de grandes similitudes en todas estas obras, cuyo análisis comparativo puede aportar datos de gran interés.

En caso de confirmarse la idea que sugerimos, los pavimentos musivos del nivel superior de La Vila Joiosa supondrían, probablemente, el conjunto más antiguo que podría adscribirse, hoy por hoy, a este taller. Su mayor antigüedad queda patente en un cierto eclecticismo, con algunas concesiones a la tradición itálica que, en el resto de ejemplos citados, va decantándose progresivamente hacia un predominio de la temática y el estilo de tradición norteafricana, caracterizada por una policromía cada vez más omnipresente.

Por último, nos queda insistir en la cronología de los pavimentos musivos de los balnea de Torre-la Cruz. A tenor de los márgenes propuestos para cada uno de los mosaicos, tenemos una datación, para los del nivel inferior, a partir de comienzos del s. III, pudiendo alcanzar fechas tan tardías como el s. V o comienzos del siguiente. En cuanto a los del superior, parece apropiada una ubicación en el segundo cuarto del s. III o poco después. Estos márgenes, basados en criterios únicamente formales, pueden concretarse con una mayor exactitud si analizamos el contexto arqueológico de las piezas.

No ofreceremos aquí una visión completa de nuestra reinterpretación del yacimiento, ya que ésta será objeto de una próxima publicación. Nos limitaremos a recoger algunos aspectos que interesan al presente estudio.

Hemos constatado, en primer lugar, la existencia de una primera fase de los balnea (Fig. 6), en la que el pasillo acodado, pavimentado con el mosaico B, conducía al único acceso exterior del apodyterium, situado en la pared SE del mismo. J. Belda señala que esta estancia careció, en su primera fase, de mosaicos, circunstancia que nos es desconocida por lo que respecta al resto de las dependencias termales. El fragmento A pavimentaba un espacio indeterminado que daba acceso al citado pasillo por su extremo SE.

En la segunda fase, que supone una auténtica reedificación, debió abrirse el vano $S$ del apodyterium, que según Belda pudo dar acceso a una escalinata descendente, rellenándose una dependencia (fig. 12, $\mathrm{n}^{\circ} 12$ ) perteneciente al sistema de combustión del nivel inferior, sobre la cual se extendió el extremo SW del corredor 4 A (54), pavimentado con el mosaico de las peltas (C). Esta nueva disposición rectilínea del pasillo, en dirección NE-SW, modificaba la del inferior. Dejando a un lado otras importantes reformas, hemos de recordar que, en este

(52) R. Mondelo $(1985,141)$ propuso la existencia de una relación entre los mosaicos de la villa de L'Algorós, en Elche, y los de Los Cipreses, en Jumilla.

(53) Según S. Ramallo (1984, 32), los de Los Cipreses o Los Torrejones son pavimentos de calidad mediocre, realizados con una pobre policromía (blanco, negro, verde y rojo), y destinados a una clientela no muy exigente. Algo similar parece ocurrir al menos en el nivel inferior de Torre-la Cruz.

(54) Hemos conservado aquí la numeración propuesta por Belda para las distintas estructuras. 
momento, se decora el piso del apodyterium con el mosaico D. A esta fase corresponden la gran mayoría, cuando no la totalidad, de las tallas murales en yeso, cuyo estudio estamos acometiendo actualmente.

Belda comenta que, entre los escombros que cubrían el derruido hipocaustum del nivel superior, apareció una moneda de Probo (276-281), lo que nos ofrece una datación post quem para el fin de la utilización de los balnea. Otras dos monedas de Claudio II (268-270) se hallaron bajo las cenizas que rellenaban el compartimento 12, probable propigneum del nivel inferior, aportando así una datación post quem para la reforma de estas instalaciones. Del análisis general del inventario del material numismático hallado por el citado autor podemos extraer otras conclusiones de interés. Hemos realizado una selección, excluyendo determinadas piezas por razones de modernidad cronológica, mal estado de conservación y consiguiente dificultad de catalogación (según Belda) o por presentar su adscripción, a nuestro juicio, ciertas dudas (55). Según nuestras estimaciones, un $88.9 \%$ de los ejemplares puede ubicarse entre el reinado de Alejandro Severo (222-235) y el de Constante (333-350). El estudio del material cerámico, procedente del cerro, depositado en el Museo Etnográfico e Histórico de Villajoyosa ratifica la fecha final de mediados del s. IV para la ocupación del yacimiento. Podemos concluir, pues, que la vida de la uilla bajoimperial de Torre-la Cruz se desarrolló entre comienzos dẹl segundo cuarto del s. III y mediados del s. IV, lapso en el que habría que enmarcar los mosaicos que presentamos aquí. Pensamos que podría proponerse una fecha del segundo cuarto del s. III o poco después para los del nivel inferior. No mucho tiempo después de 268, a juzgar por las características de los pavimentos C y D, se produjo la reedificación de estas instalaciones. Tendríamos, por tanto, una fecha en torno a finales del tercer cuarto del s. III para los mosaicos del nivel superior, aparentemente algo tardía, sobre todo para el de las peltas (C). De hecho, en este caso nos encontraríamos con uno de los ejemplares conocidos de fecha más avanzada entre los pavimentos bícromos de Hispania, ya que prácticamente no se conocen casos de la segunda mitad del siglo.

Creemos que la causa directa de la reedificación de los balnea debió ser una destrucción atestiguada por la existencia, bajo el empedrado de cantos que constituía el lecho del mosaico $\mathrm{D}$, de "un piso de tierra muy dura e intensamente quemada", producto de un incendio, según Belda. Desconocemos el grado en el que afectó al resto de la uilla, aunque ciertas reformas, como el cambio de disposición del pasillo 4, nos hacen pensar en una cierta reordenación de los espacios. Creemos que podría ponerse en relación estos hechos con las invasiones germánicas del s. III y la inestabilidad general provocada por las mismas. Como es bien sabido, la irrupción de estos pueblos en Hispania se produjo hacia 260. Numerosos hallazgos de ocultaciones monetales de la Península Ibérica, algunos de ellos efectuados en nuestra provincia, presentan fechas-límite próximas a ésta (González Prats-Abascal, 1987), mientras importantes núcleos como el Tossal de Manises son destruidos. Valga esta última disgresión para resaltar la importancia del yacimiento de Torre-la Cruz dentro del contexto de la Arqueología clásica del País Valenciano. Esperamos que futuros trabajos puedan incrementar nuestros actuales conocimientos al respecto.

(55) Del total de 50 ejemplares inventariados por Belda (1948, 168-169) hemos desestimado los números 1 a $3,13,37$ y 42 a 50. Es posible que existan errores de interpretación, pero dada la elevada cantidad de ejemplares estimamos que nuestros cálculos pueden tener una ciertaa fiabilidad. Esperamos que los trabajos de identificación de distintos lotes numismáticos que se están llevando a cabo en el Museo Arqueológico Provincial de Alicante puedan culminar con la reintegración de este conjunto, lo que posibilitaría su revisión. 


\section{POST SCRIPTUM}

Ya entregado este trabajo para su publicación, ha visto la luz un artículo de S. Ramallo ("Talleres y escuelas musivarias en la Península Ibérica"), en Mosaicos Romanos. Estudios sobre iconografia. Actas del Homenaje a Alberto Balil Illana, Guadalajara, 1990, 135-180) cuyas conclusiones respecto a la existencia de un taller bajoimperial en el Sudeste hispano, que este autor ubica en Illici, concuerdan básicamente con las nuestras (op cit., 167-168). A los conjuntos citados por él podrían añadirse, como ya se ha expuesto anteriormente, el de Los Torrejones (Yecla) y el de Torre-la Cruz, que supone, en la actualidad, el exponente más temprano de este taller. 


\section{BIBLIOGRAFIA}

ABASOlO, J. A. 1983: "Excavaciones en San Martín de Losa (Burgos)”, Noticiario Arqueológico Hispánico $15,233-270$.

ACUÑA, F. 1972: "Los mosaicos de La Cigarrosa (Orense)", Boletin del Seminario de Arte y Arqueologia 38, 468 ss.

... 1973: "Mosaicos romanos de Hiapania Citerior II: Conventus Lucensis", Studia Archaeologica 24.

... 1974: "Mosaicos romanos de Hispania Citerior III: Conventus Bracarensis", Studia Archaeologica 31.

AleXANDer, M. A. et al. 1973: Corpus des Mosaïques de Tunisie I, 1, Tunis.

... et al. 1980: Corpus des Mosaïques de Tunisie II, 1, Tunis.

ALMAGRo BASCH, M. 1968: Ampurias, guía de las excavaciones y del Museo, Barcelona.

Anglolillo, S. 1981: Mosaici Antichi in Italia. Sardinia, Roma.

BALIL, A. 1960: "Arte Helenístico en el Levante Español. Mosaico con representación de peces hallado en Ampurias", Boletín de la Real Academia de la Historia CXLVI, 267-310.

... 1961: "Mosaico con escenas portuarias hallado en Toledo", Homenaje al Prof. Cayetano de Mergelina, Murcia.

... 1962: "Mosaicos ornamentales romanos de Barcelona", Archivo Español de Arqueologia XXXV, 36-39.

... 1964: "Mosaicos romanos de Baetulo (Badalona)", Zephyrus XV, 85-100.

... 1965 a: "Algunos mosaicos hispanorromanos de época tardía", Príncipe de Viana 26, 281-294.

... 1965 b: "Las escuelas musivarias del Conventus Tarraconensis”, La Mosaïque Greco-Romaine I, 23-39.

... 1970: "Estudios sobre mosaicos romanos I", Studia Archaeologica 6.

... 1973: "Estudios sobre mosaicos romanos III", Studia Archaeologica 25.

... 1975: "Sobre los mosaicos romanos de Galicia: identificación de un taller musivario", La Mosäque Greco-Romaine II, 259 ss.

... 1979: "Mosaico con representación de las Nueve Musas hallado en Moncada (Valencia)", Bol. del Seminario de Arte y Arqueologia XLV, 19-30.

BALIL, A.-MAÑANES, T. 1980: “Estudios sobre mosaicos romanos VII”, Studia Archaeologica 59.

BALIL, A.-Mondelo, R. 1985: "Mosaico con representación de peces hallado en las proximidades de Tarragona", Bol. del Seminario de Arte y Arqueología LI, 251-256.

BARRAL, X. 1978: Les mosaïques romaines et médiévales de la Regio Laietana (Barcelone et ses environs), Barcelona.

... 1979: "Els mosaics d'Empuries. Informació preliminar", Faventia I/1, 71-76.

BECCATI, G. 1961: Scavi di Ostia IV. Mosaici e pavimenti marmorei, Roma.

BELDA, J. 1946: "Ingresos procedentes del cerrillo de Torre-la Cruz", Memorias de los Museos Arqueológicos Provinciales VII, 143 ss.

... 1947: "Ingresos procedentes de Torre-la Cruz", ibidem. VIII, 167 ss.

... 1948: "Nuevos ingresos procedentes del cerrillo de Torre-la Cruz", ibidem. IX, 167 ss.

BELZ, C. 1980: Marine genre mosaic pavements of Roman North Africa, London.

BEN ABED, A. et al. 1985: Corpús des Mosaïques de Tunisie II, 2, Tunis.

BERTI, G. 1976: Mosaici Antichi in Italia, Reg. Ottava, Ravenna I, Roma.

BLAKE, M. E. 1930: "Pavements of Roman buildings of the Republic and Early Empire", Memoirs of the American Academy in Rome VIII, 7-159.

Blanco, A. 1978 a: Corpus de Mosaicos de España I, Madrid.

... 1978 b: Corpus de Mosaicos de España II, Madrid. 
BLANCHARD et al. 1973: "Repertoire graphique du décor géometrique dans la mosaïque", Bull. de l'Association Internationale pour l'Etude de la Mosaïque Antique 4.

BLANCHET, M. A. 1909: Inventaire des mosaïques de la Gaule II, París.

BLASCO, C. 1971: "Restos de un mosaico romano en Utebo (Zaragoza)", XII Congreso Nacional de Arqueologia, Jaén, 719-726.

BlazQUEZ, J. M. 1981: Corpus de Mosaicos de España III, Madrid.

... 1982 a: Corpus de Mosaicos de España IV, Madrid.

... 1982 b: Corpus de Mosaicos de España V, Madrid.

... et al. 1989 a: Corpus de Mosaicos de España IX, Madrid.

... 1989 b: Corpus de Mosaicos de España VIII, Madrid.

Blazquez, J. M.-Gonzalez NaVARrete, J.: “Mosaicos Hispánicos del Bajo Imperio", Archivo Español de Arqueologia 45-47, 419-438.

Blazquez, J. M.-Ortego, T. 1983: Corpus de Mosaicos de España VI, Madrid.

Bobadilla, M. 1969: "El mosaico de peces de La Pineda", Pyrenae 5, 141-155.

BONSOR, G. 1931: The archaeological expedition along the Guadalquivir, New York.

BRUsin, G. 1961: Due nuovi sacelli cristiani di Aquileia, Aquileia.

CaVAnilles, A. J. 1797 (1943): Geografia del Reyno de Valencia, vol. II, Valencia.

... 1797 (1970): "Excavaciones en Calpe", Studia Archaeologica 5.

Clouzot, E. 1935: "Note sur la mosaïque de Nyon", Genava XIII, 235 ss.

CUNLIFE, B. 1971: Fishbourne, a Roman palace and its garden, London.

DEPUMA, R. D. 1980: The Roman fish mosaic, London.

Duliere, C. et al. 1974: Corpus des Mosaïques de Tunisie I, 2, Tunis.

Fernandez CAStro, M. C. 1978: "Las llamadas "termas" de Rielves (Toledo)", Archivo Español de Arqueología 50-51, 209-252.

... 1982: "Apéndice”, en Corpus de Mosaicos de España V (Blázquez, 1982 b), 61-75.

FernandeZ-Galiano, D. 1984: Complutum II. Mosaicos, Madrid.

... 1987: Mosaicos romanos del Conventus Caesaraugustano, Zaragoza.

FERNANDEZ OCHOA, C. 1982: Asturias en la época romana, Madrid.

FOUCHER, L. 1958: Thermes romaines des environs d'Hadrumete, Tunis.

... 1960: Inventaire des Mosaïques. Feuille no 57 de l'Atlas Archéologique de Sousse, Tunis.

Fradier, G.-Martin, A. 1976: Mosaïques de Tunisie, Tunis.

Garcia GuINEA, M. A. 1982: Guia de la villa romana de Quintanilla de la Cueza, Palencia.

Garcia Merino, C. 1971: "La ciudad romana de Uxama, V", Bol. del Seminario de Estudios de Arte y Arqueologia XXXVII, 86 ss.

GaRCIA SANDOVAL, E. 1966: Informe sobre las casas romanas de Mérida y excavaciones en la "Casa del Anfiteatro", Madrid.

GARCIA Y BELLIDO, A. 1953: "Dos "villae rusticae" romanas recientemente excavadas", Archivo Español de Arqueologia XXVI, 207-216.

Germain, S. 1969: Les mosaïques de Timgad, París.

Gonzalez Prats, A.-Abascal, J. M. 1987: “La ocultación monetal de la D’Eula (Crevillente, Alicante) y su significación para el estudio de las invasiones del S. III”, Lucentum VI, 183-196.

Hernandez DiAz, J. et al. 1943: Carmona, catálogo arqueológico y artístico, Sevilla.

LAFUente J. 1959: Museo Arqueológico Provincial de Alicante. Catálogo-guía, Alicante.

LANCHA, J. 1977: Mosaïques geométriques. Les ateliers de Vienne, Roma.

LAVAGNE, H. 1979: Recueil général des mosaiques de la Gaule III, 1, París. 
LEVI, D. 1947: Antioch Mosaic Pavements, Princeton.

LuZon, J. M. 1988: "La roseta de triángulos curvilíneos en el mosaico romano", Gerión, Anejos I, Homenaje a García y Bellido V, Madrid.

ManO-ZisSI, D. 1965: "La question des differents ècoles de mosaïques greco-romaines de Yugoslavie et essai d'une esquisse de leur evolution”, La Mosaïque Greco-Romaine I, París.

MingaCcini, P. 1966: L'Insula di Giasone Magno a Cirene, Roma.

MONDElo, R. 1985: "Los mosaicos de la villa romana de Algorós (Elche)", Bol. del Seminario de Estudios de Arte y Arqueologia LI, 107-141.

Mondelo, R.-Torres, M. 1985: "El mosaico romano de Casariche", Bol. del Seminario de Estudios de Arte y Arqueologia LI, 143-155.

Morricone, M. L. 1967: Mosaici antichi in Italia, Reg. Prima. Roma: Reg. X Palatino, Roma.

Nieto Gallo, G. 1943: "La villa romana de Almenara de Adaja (Valladolid), Bol. del Seminario de Estudios de Arte y Arqueologia, 197-198.

Nobrega, I. 1951: “O mosaico luso-romano de Póvoa de Cós”, O Arqueólogo Portugués, nova serie, I.

OVADIAH, A. 1980: Geometric and floral patterns in ancient mosaics, Roma.

PAlOL, P. 1963: "El mosaico de tema oceánicode la villa de Dueñas (Palencia)", Bol. del Seminario de Estudios de Arte y Arqueologia XXIX, 5-34.

... 1967: Arqueologia Cristiana de la Hispania Romana, Valladolid.

PARLaSCA, K. 1959: Die Römischen mosaiken in Deutschland, Berlín.

PELEKANIDIS, S. 1974: Corpus mosaicorum christianorum vetustiorum pavimentorum I, Thesalonica.

Peluicer, M. 1965: "Excavaciones en el yacimiento romano de los "Bańos de la Reina”, Calpe (Alicante), Noticiario Arqueológico Hispánico VIII-IX, 172-176.

PICARD, G. CH. 1949: "Rapport des Fouilles", Bulletin Archeologique du Comité des Travaux Historiques et Scientifiques, 175-176.

PICARD, G. CH. 1960: “Mosaïques africaines du IIIe S. ap. J. C.”, Revue Archéologique II.

PRUDHOMME, 1975: "Recherches des principes de construction des mosaïques géometriques romaines", La Mosaïque Greco-Romaine II.

Ramallo, S. F. 1984: El mosaico romano en Murcia, Murcia.

... 1985: Mosaicos romanos de Carthago Nova (Hispania Citerior), Murcia.

Sanchez Fernandez, M. J.-Blasco, E.-Guardiola, A. 1986: Portus Illicitanus: datos para una sintesis, Alicante.

SANCHEZ REAL, J. 1949: "Descubrimientos recientes: mosaicos romanos de Senna”, Boletín Arqueológico 26-28, 224 ss.

Santa Maria, V.-Morricone, M. L. 1975: Mosaici Antichi in Italia, Regione Prima, Antium, Roma.

SMITH, D. J. 1975: "Roman mosaics in Britain before the Fourth Century", La Mosaïque GrecoRomaine II.

SOLER, L. 1921: "Ciudades levantinas: Villajoyosa”, La Esfera, 15 de Enero de 1921.

SpINAzZola, V. 1953: Pompei alla luce degli scavi nuovi di via dell'Abbondanza, Roma.

STERN, H. 1959: “Origine et débuts de la mosaïque murale", Annales de l'Est 22.

... 1967: Recueil général des mosaïques de la Gaule II, 1, París.

Taracena, B. 1941: Carta Arqueológica de España. Soria, Madrid.

Thouvenot, R. 1948 a: "La Maison eux Travaux d'Hercule", Publications du Service des Antiquités du Maroc 8, 69-108.

... 1948 b: "Le Quartier Nord-Est. La rive droite du Decumanus Maximus", ibidem, 109-144. 
... 1958: "Maisons de Volubilis: le Palais dit de Gordien et la Maison a la Mosaïque de Venus", ibidem 12.

ThOUVENOT, R.-LuQUet, A. 1951: "Le "macellum" et les batiments voisins", ibidem 9, 81-100.

Ventura Solsona, S. 1962: Museo Arqueológico Provincial de Tarragona. Guía del Visitante, Tarragona. 